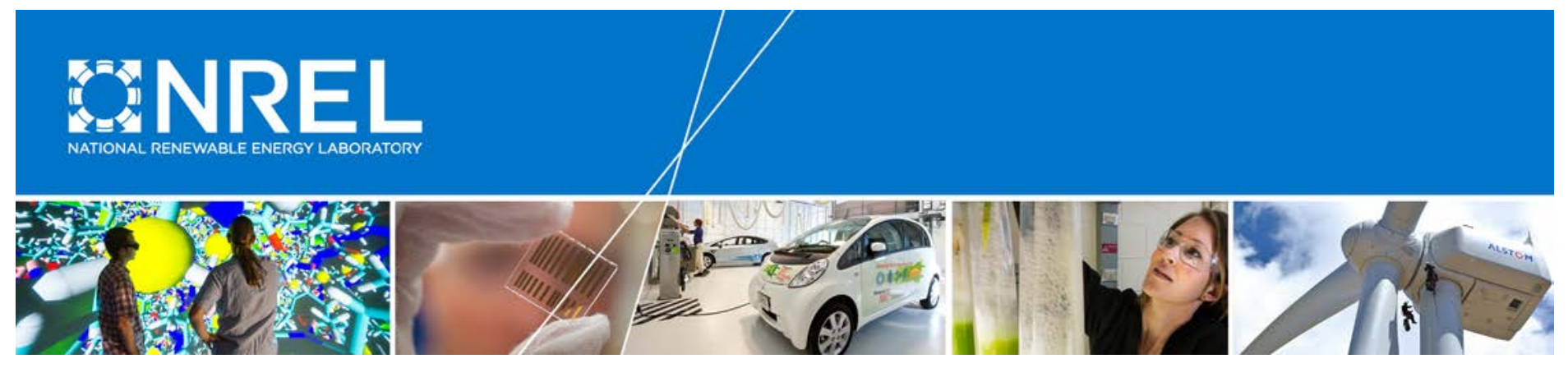

\title{
Autonomy-Enabled Fuel Savings for Military Vehicles: Report on 2016 Aberdeen Test Center Testing
}

Adam Ragatz, Robert Prohaska, and Jeff Gonder National Renewable Energy Laboratory

NREL is a national laboratory of the U.S. Department of Energy Office of Energy Efficiency \& Renewable Energy Operated by the Alliance for Sustainable Energy, LLC

This report is available at no cost from the National Renewable Energy Laboratory (NREL) at www.nrel.gov/publications.

Technical Report

NREL/TP-5400-67665

May 2017 


\section{Autonomy-Enabled Fuel Savings for Military Vehicles: Report on 2016 Aberdeen Test Center Testing}

Adam Ragatz, Robert Prohaska, and Jeff Gonder National Renewable Energy Laboratory

Prepared under Task No. WFJG.1000

NREL is a national laboratory of the U.S. Department of Energy Office of Energy Efficiency \& Renewable Energy Operated by the Alliance for Sustainable Energy, LLC

This report is available at no cost from the National Renewable Energy Laboratory (NREL) at www.nrel.gov/publications.

National Renewable Energy Laboratory 15013 Denver West Parkway Golden, CO 80401

303-275-3000 • www.nrel.gov

\section{Technical Report}

NREL/TP-5400-67665

May 2017

Contract No. DE-AC36-08G028308 


\section{NOTICE}

This report was prepared as an account of work sponsored by an agency of the United States government. Neither the United States government nor any agency thereof, nor any of their employees, makes any warranty, express or implied, or assumes any legal liability or responsibility for the accuracy, completeness, or usefulness of any information, apparatus, product, or process disclosed, or represents that its use would not infringe privately owned rights. Reference herein to any specific commercial product, process, or service by trade name, trademark, manufacturer, or otherwise does not necessarily constitute or imply its endorsement, recommendation, or favoring by the United States government or any agency thereof. The views and opinions of authors expressed herein do not necessarily state or reflect those of the United States government or any agency thereof.

This report is available at no cost from the National Renewable Energy Laboratory (NREL) at www.nrel.gov/publications.

Available electronically at SciTech Connect http:/www.osti.gov/scitech

Available for a processing fee to U.S. Department of Energy and its contractors, in paper, from:

U.S. Department of Energy

Office of Scientific and Technical Information

P.O. Box 62

Oak Ridge, TN 37831-0062

OSTI http://www.osti.gov

Phone: 865.576.8401

Fax: 865.576.5728

Email: reports@osti.gov

Available for sale to the public, in paper, from:

U.S. Department of Commerce

National Technical Information Service

5301 Shawnee Road

Alexandria, VA 22312

NTIS http://www.ntis.gov

Phone: 800.553 .6847 or 703.605 .6000

Fax: 703.605.6900

Email: orders@ntis.gov 


\section{Acknowledgments}

The authors acknowledge that funding for the work performed within the Autonomy-Enabled Fuel Savings for Military Vehicles project is provided by the Office of the Deputy Assistant Secretary of Defense for Operational Energy (ODASD(OE)) Operational Energy Capabilities Improvement Fund (OECIF) Program. TARDEC greatly appreciates the support it has received from the Director of Innovation and staff of ODASD(OE) within the Office of the Assistant Secretary of Defense for Energy, Installations \& Environment. 


\section{List of Acronyms}

AMAS

ATC

ATEF

CAN

CTA

GPS

$\mathrm{kg}$

$\mathrm{kW}$

$\mathrm{lb}$

mph

MTA

NREL

PTA

SAE

TARDEC
Autonomous Mobility Appliqué System

Aberdeen Test Center

Automotive Technology Evaluation Facility

controller area network

Churchville Test Area

global positioning system

kilogram

kilowatt

pound

miles per hour

Munson Test Area

National Renewable Energy Laboratory

Perryman Test Area

SAE International

Tank Automotive Research, Development, and

Engineering Center 


\section{Table of Contents}

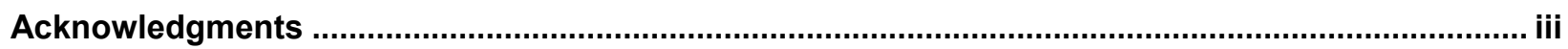

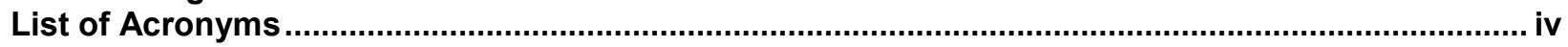

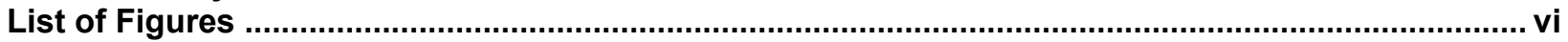

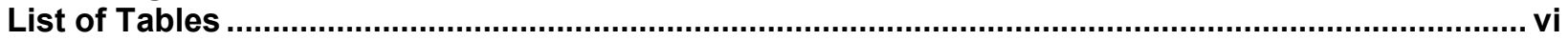

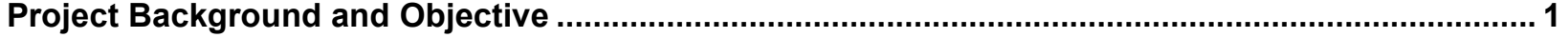

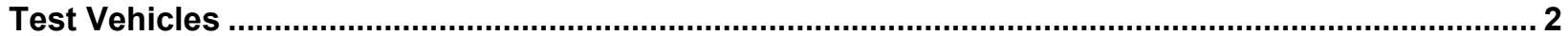

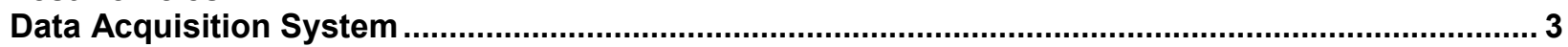

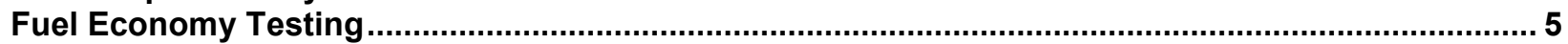

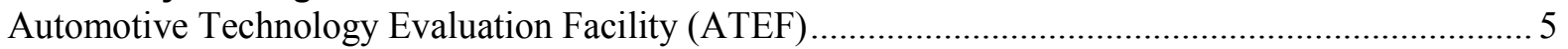

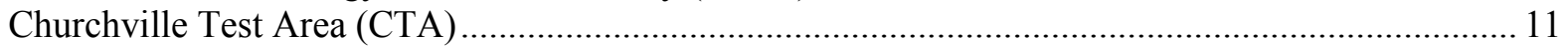

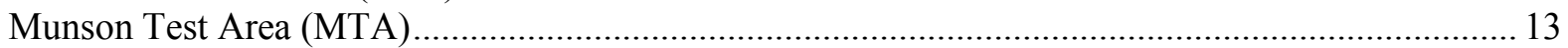

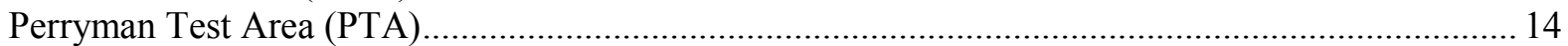

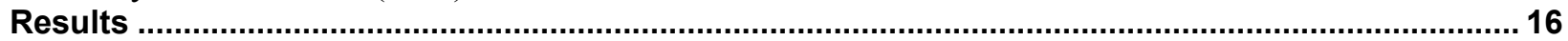

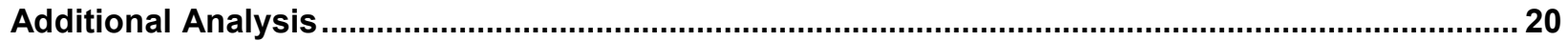

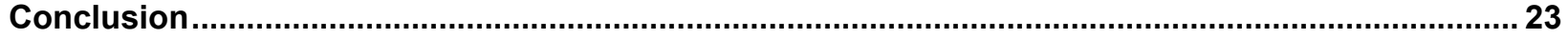

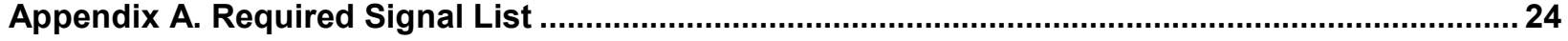

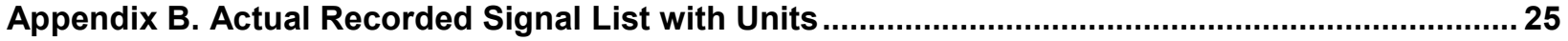

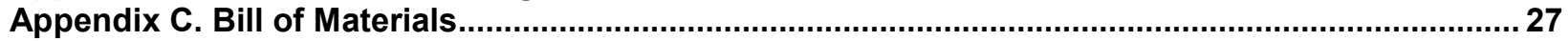

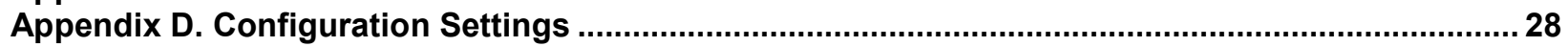




\section{List of Figures}

Figure 1. AVL KMA Mobile, 1 - Measuring Module, 2 - Conditioning Module ..................................... 3

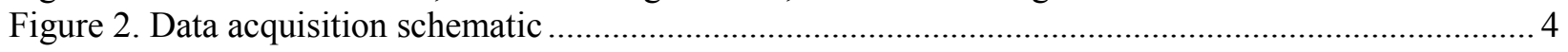

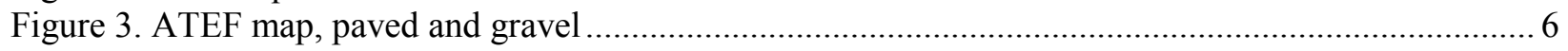

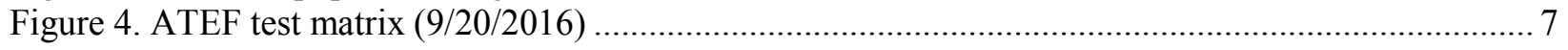

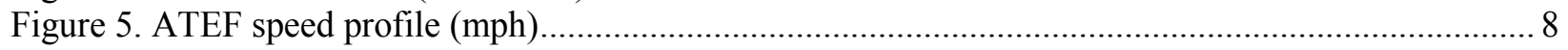

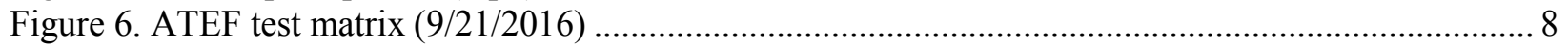

Figure 7. Allison transmission control pad (left) and transmission (right) .......................................... 9

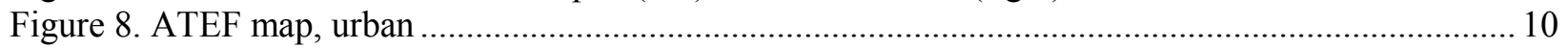

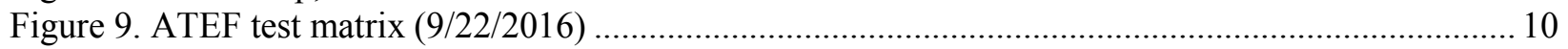

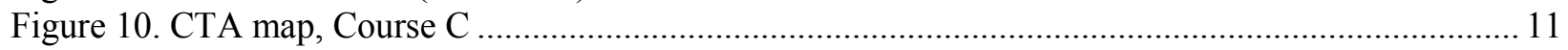

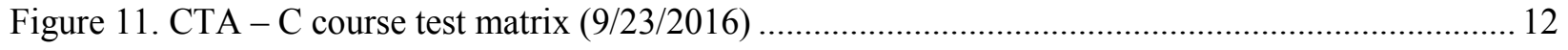

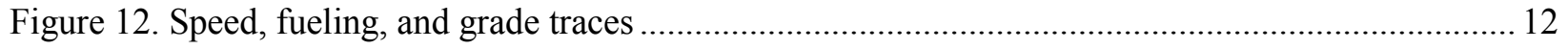

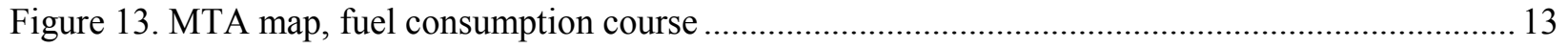

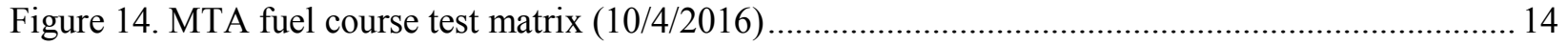

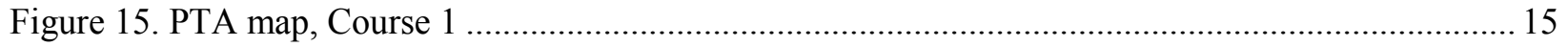

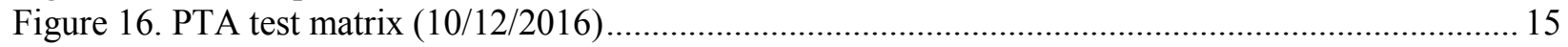

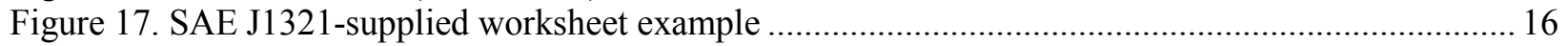

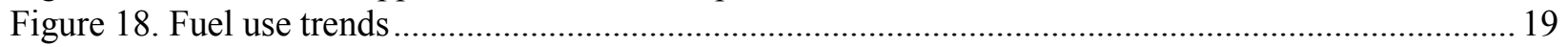

Figure 19. Fuel savings from various modes of operation............................................................... 20

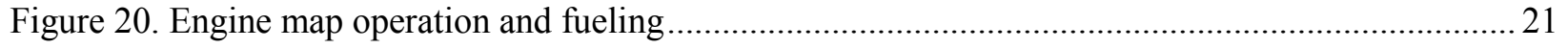

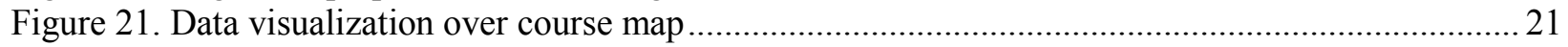

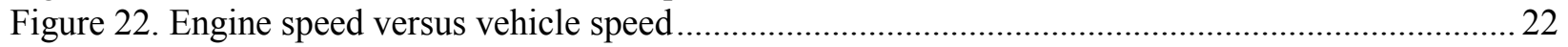

\section{List of Tables}

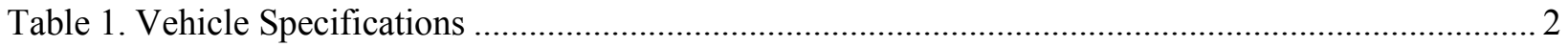

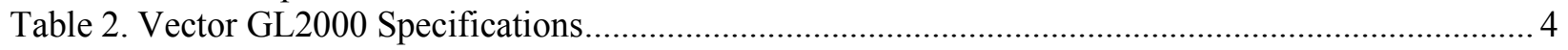

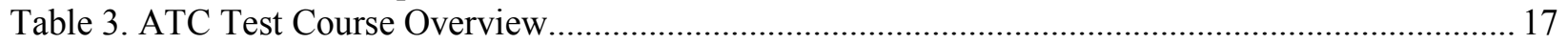

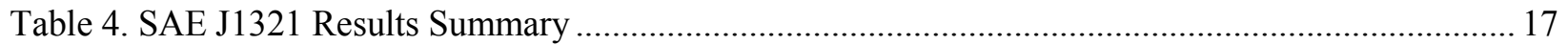

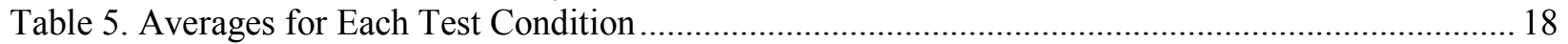




\section{Project Background and Objective}

Research into autonomy-enabled military vehicles has historically been motivated by concerns over personnel safety and operation efficiency, with less attention given to the potential for fuel savings. However, studies have estimated that autonomy in passenger and commercial vehicles could improve fuel economy by as much as $22 \%-33 \%{ }^{1,2}$ over various drive cycles. If even a fraction of this saving could be realized in military vehicles, significant cost savings could be realized each year through reduced fuel transport missions, reduced fuel purchases, less maintenance, fewer required personnel, and increased vehicle range. This autonomy-enabled vehicle project targets achieving broad fuel savings in excess of $5 \%$ over conventionally operated vehicles.

The National Renewable Energy Laboratory (NREL), located in Golden, Colorado, has supported this continued effort under Interagency Agreement IAG-15-1980 by installing instrumentation and data collection systems on-board test vehicles and analyzing the collected results to determine system performance and improve on the control strategy. The information presented in this report describes the test vehicles, additional instrumentation, and the data acquisition system added by NREL and presents preliminary results from the first round of testing. These results will be used to iterate on the system design and control strategy ahead of further planned testing in 2017 and 2018.

In addition to NREL's role outlined above, other key project contributors include:

- The Office of the Deputy Assistant Secretary of Defense for Operational Energy provided the funding for this project.

- The U.S. Army Tank Automotive Research, Development, and Engineering Center (TARDEC), the project's principal investigator, is responsible for leading the project and implementing the custom control strategy to manipulate the original equipment manufacturer's signals onboard the vehicle.

- The U.S. Army Aberdeen Test Center (ATC) at the Aberdeen Proving Grounds provided testing support and equipment and made the various test tracks available for this fuel economy testing.

- Argonne National Laboratory - is responsible for constructing the model-based custom control strategy and delivering it to TARDEC for implementation.

- Lockheed Martin - is responsible for the design and construction of the Autonomous Mobility Appliqué System (AMAS), the base autonomy kit for these military vehicles.

- Primus Solutions Inc. - handled custom fabrication, component installation, and vehicle logistics.

\footnotetext{
${ }^{1}$ Manzie, C., et al., 2007, "Fuel Economy Improvement for Urban Driving: Hybrid vs. Intelligent Vehicles." Transportation Research Part C 15, Elsevier, 1-16

${ }^{2} \mathrm{Wu}, \mathrm{C}$., et al., 2011, “A Fuel Economy Optimization System with Applications in Vehicles with Human Drivers and Autonomous Vehicles.” Transportation Research Part D 16, 515-524.
} 


\section{Test Vehicles}

The test vehicles used for this autonomy-enabled fuel economy assessment were two different variants of the M915. The M915 is a military specification version of a typical over-the-road class $86 \times 4$ vocational tractor. The first vehicle, an M915A3, was configured as an unarmored day cab, and the second vehicle, an M915A5, was configured as an extended cab up-armored version of the M915. Both vehicles were powered by Detroit Diesel S60 series diesel engines with automatic transmissions. Each was connected to separate M872A3 flatbed trailers for the testing. The trailers were loaded with intermodal shipping containers and ballasted to near their gross combined weight ratings. Specifications are shown in Table 1.

Table 1. Vehicle Specifications

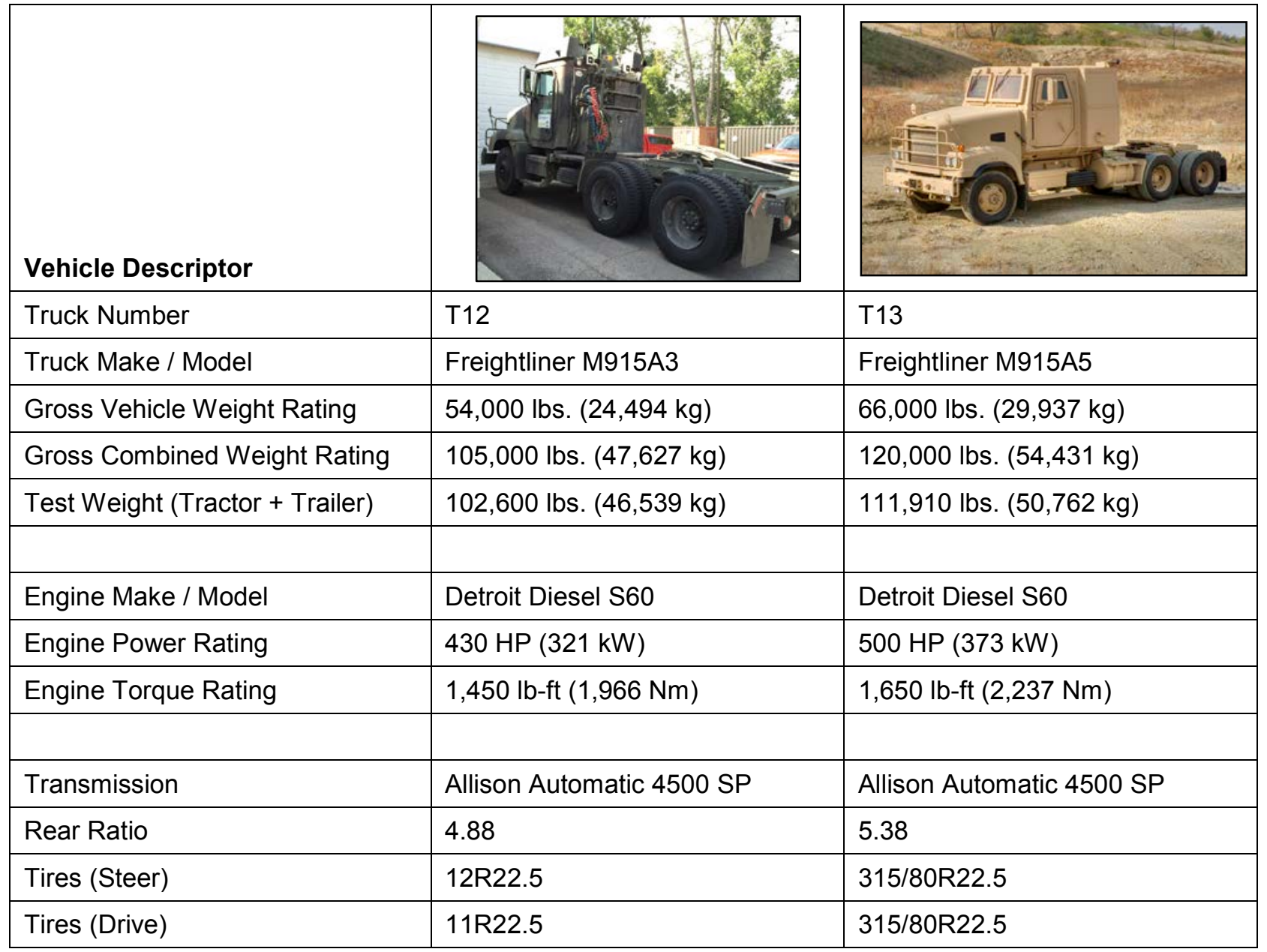

Photos: M915A3 - R. Prohaska NREL | M915A5 - TARDEC 


\section{Data Acquisition System}

Early in the project planning phase, a number of group discussions were held to determine the required data channels to capture so that all parties would be able to perform the necessary analysis. Some of these channels were available from the on-board diagnostic J1939 controller area network (CAN) bus, but other channels required adding additional instrumentation. The full negotiated required channel list is shown in Appendix A. However, the actual captured channel list exceeded the minimum requirements and is shown in Appendix B along with the channel units as recorded.

In addition to the legislated CAN channels available from each vehicle's on-board diagnostic network, NREL added thermocouples, pressure transducers, a GLONASS-enabled global positioning system (GPS), and a weather station. The system also included provisions to log the data stream from the high-accuracy AVL KMA mobile fuel flow meter installed by Primus Solutions shown in Figure 1. Data were recorded from the fuel flow meter in two ways, through a high-speed frequency-to-analog converter connected to the pulse output and an RS-232-toCAN converter connected to the serial output. All signals were converted to a CAN where necessary and logged using a Vector GL2000 data recorder. The Vector GL2000 loggers were selected for their ability to log multiple CAN buses, which allowed for easy expansion, and the ability to connect with a Wi-Fi or cellular network for periodic data uploads. Additional specifications for the Vector GL2000 loggers are shown in Table 2. A schematic of the system is shown in Figure 2.

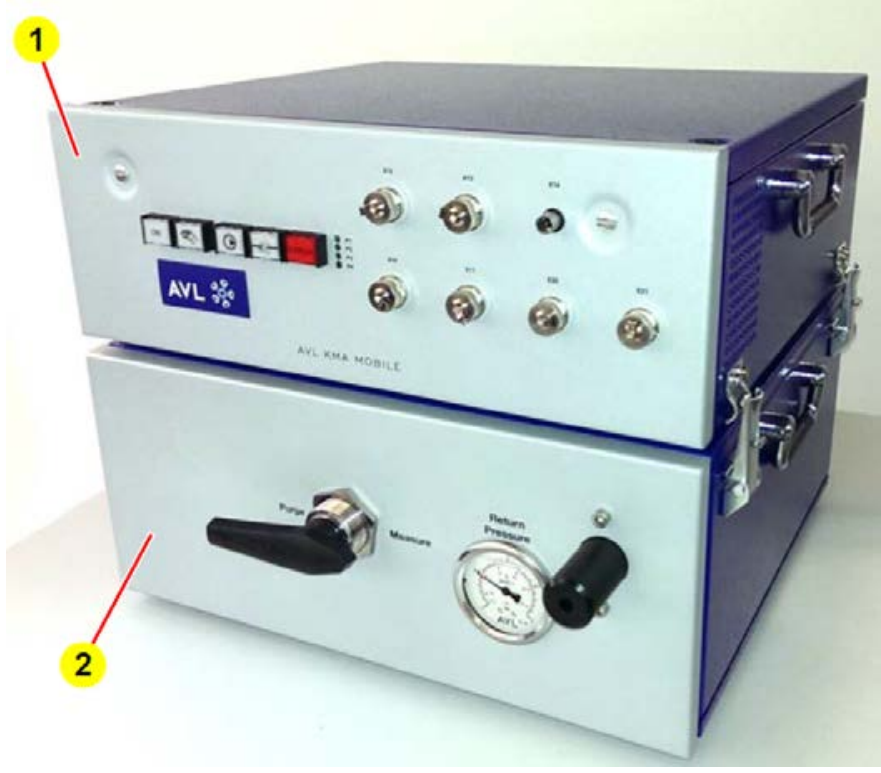

Figure 1. AVL KMA Mobile, 1 - Measuring Module, 2 - Conditioning Module Photo by $A V L$ 
Table 2. Vector GL2000 Specifications

\begin{tabular}{|l|l|}
\hline Technical Data & Description \\
\hline CAN channels & $\begin{array}{l}\text { CAN1 }-2: \text { 2x fixed high-speed, wake-up capable } \\
\text { CAN3 }-4: \text { 2x user-configurable }\end{array}$ \\
\hline Memory & SD memory cards up to 2 GB, SDHC up to 32 GB \\
\hline Display & 4 user-configurable LEDs \\
\hline Inputs, outputs & $\begin{array}{l}4 \text { analog inputs } \\
4 \text { digital inputs / outputs }\end{array}$ \\
\hline Wireless data transmission & $3 \mathrm{G} /$ UMTS or WLAN $802.11 \mathrm{~b} / \mathrm{g}$ \\
\hline Supply voltage & $6 \mathrm{~V}-30 \mathrm{~V}$ \\
\hline & $\begin{array}{l}\text { Sleep mode: typically }<1 \mathrm{~mA} \\
\text { Standby mode: typically } 60 \mathrm{~mA} \\
\text { Operating: typically } 170 \mathrm{~mA}\end{array}$ \\
\hline
\end{tabular}

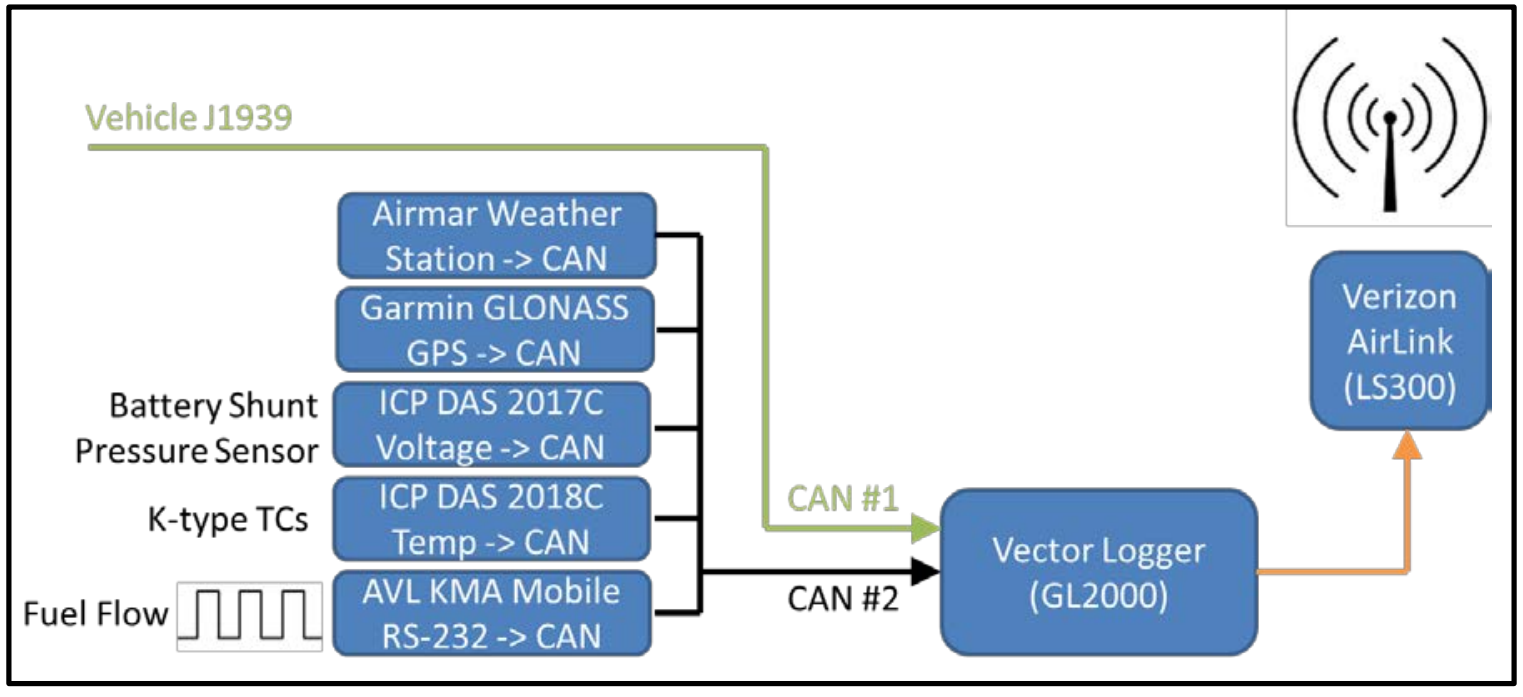

Figure 2. Data acquisition schematic

For additional information, a detailed bill of materials is included in Appendix C. A number of these modules required initial setup. Detailed documentation of the configuration settings for each module is included in Appendix D. 


\section{Fuel Economy Testing}

The procedure used for this fuel economy testing followed the general guidelines of SAE International (SAE) Standard J1321 "Fuel Consumption Test Procedure - Type II." ${ }^{3}$ The SAE J1321-supplied calculation utility was used to calculate the nominal fuel economy improvement and corresponding $95 \%$ confidence interval from the raw fuel use data where applicable. For both vehicles, there were generally three modes of operation:

- Manual / Baseline: In this mode, the driver handles all functions of operating the vehicle. This mode is used as the baseline condition. Speed control is maintained with manual manipulation of the accelerator pedal, brake pedal, and engine brake.

- AMAS Cruise: In this mode the driver still steers the vehicle, but all speed control functions are handled by the standard Lockheed Martin AMAS Cruise control system.

- Smart Cruise: This mode is similar to AMAS Cruise, but the AMAS Cruise control messages are manipulated by the model-based control strategy developed by Argonne National Laboratory and implemented by TARDEC. This strategy allows the actual speed to deviate more than usual from the commanded set speed in an effort to maximize fuel savings.

Each day of testing began with a number of warm-up laps until fuel economy and vehicle component temperatures stabilized. Testing began with three to five acceptable runs at each condition, starting with manual / baseline. If track time permitted, one vehicle remained in manual/baseline while the other vehicle went through each test condition, and then they switched conditions. This is the typical procedure for a Type II track test so the control vehicle can be used to normalize the results and account for changing environment conditions during testing. However, for some scenarios time did not allow for a full control vehicle test, and both vehicles ran through the test sequence at the same time. All testing was conducted at ATC at four different test areas. At some locations testing was repeated at various speeds and on various surfaces. The following sections describe the courses and test schedules and provide maps of each testing area.

\section{Automotive Technology Evaluation Facility (ATEF)}

The Automotive Technology Evaluation Facility (ATEF) track is a flat multi-surface, paved and gravel, 4.5-mile-long tri-oval around the Phillips Army Airfield. The paved surface has two lanes that go all the way around the airfield, with the single-lane gravel surface on the outside separated from the track by a grass median. Figure 3 shows a map of the track along with the location of crossing \#1, which was used as the start and finish point for each lap. The vehicles began and ended each lap at speed, and continuously recorded data were split by lap using the geo-marker shown on the map. All testing was conducted in a counter-clockwise direction.

\footnotetext{
${ }^{3}$ Fuel Consumption Test Procedure - Type II, https://saemobilus.sae.org/content/j1321_201202
} 


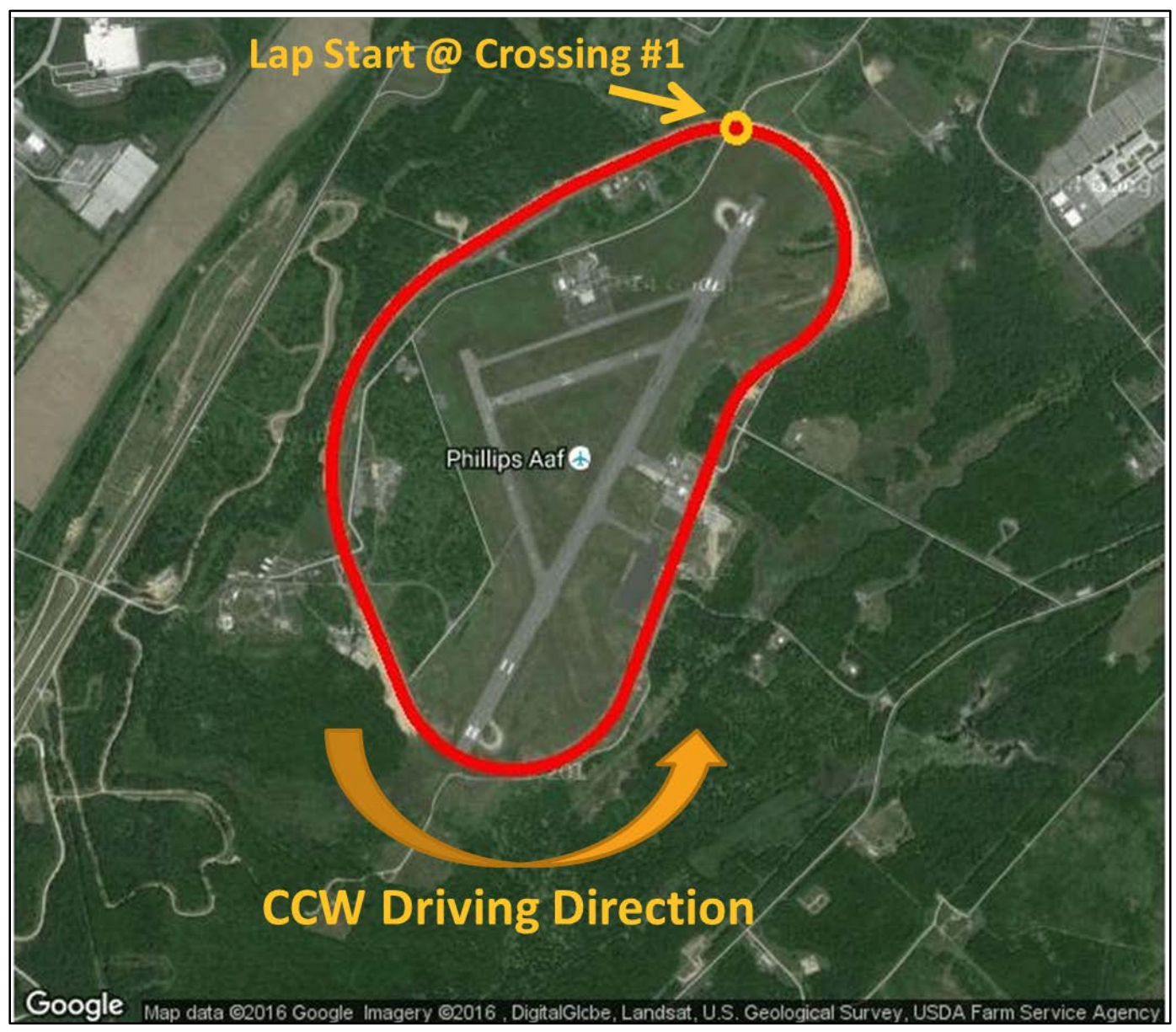

Figure 3. ATEF map, paved and gravel

๑) Google Maps

The test matrix for ATEF spanned three days. The first day focused on conducting a comparison of manual/baseline, AMAS Cruise, and Smart Cruise all on the paved surface. For this comparison, both vehicles where driven on the track at the same time 180 degrees apart. One vehicle continuously ran the baseline condition as the control truck as the other vehicle cycled through the various test conditions. Then, after a short break they switched. Figure 4 shows this schedule graphically. 


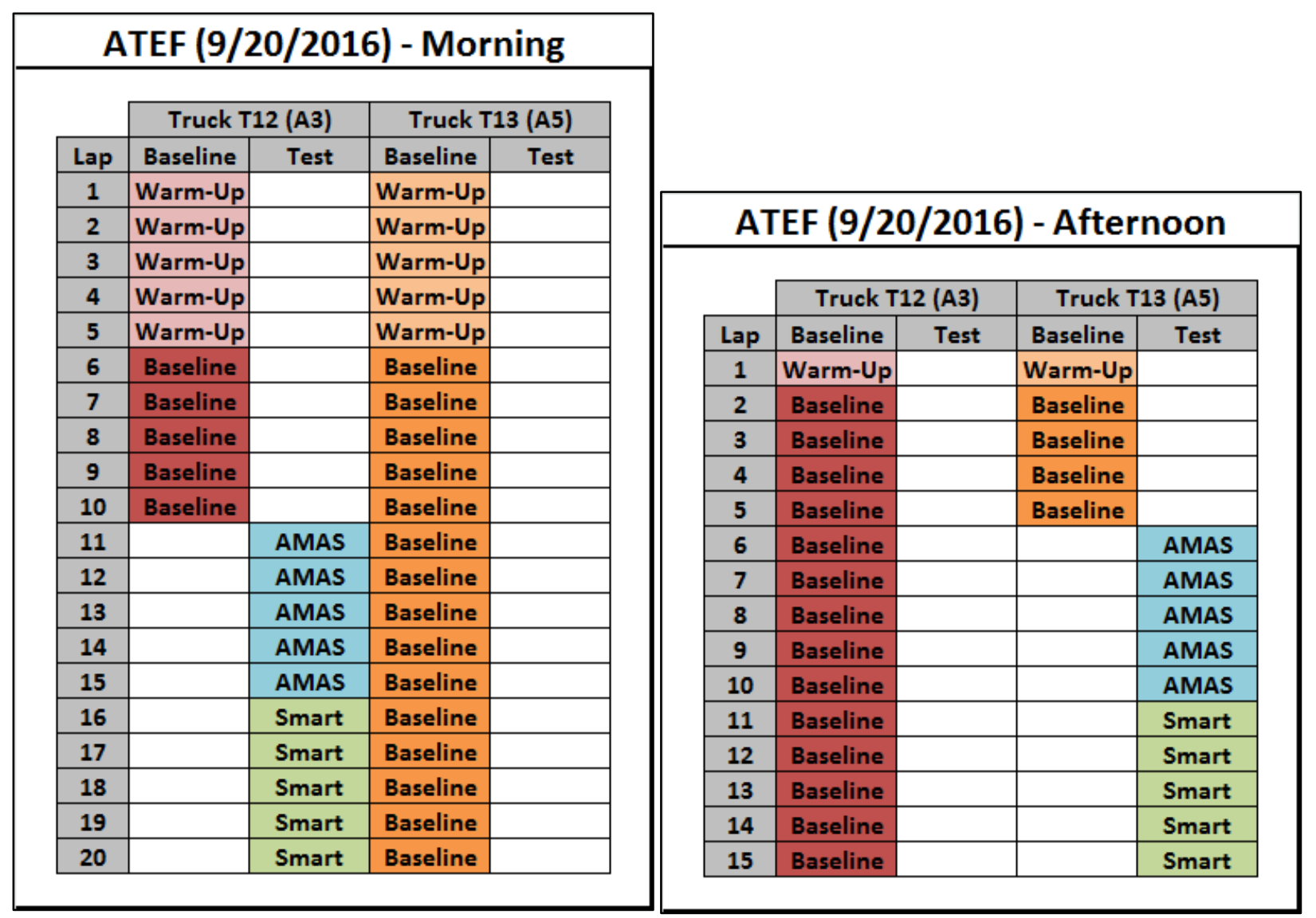

Figure 4. ATEF test matrix (9/20/2016)

The target speed for all conditions was 50 miles per hour (mph) in the straights and $40 \mathrm{mph}$ in the curves. This is shown graphically in Figure 5. Although the Smart Cruise system was commanded to operate at these speeds, the model chose $45 \mathrm{mph}$ and $35 \mathrm{mph}$, respectively, as more optimal operating speeds. Because of this, it was decided that the next day would begin with a manual/baseline test mimicking the Smart Cruise speeds in an effort to separate cruise control effects from speed set point effects. The schedule for day two is shown in Figure 6. Once the reduced-speed manual condition tests were finished, testing moved to the gravel course that runs on the outside of ATEF parallel with the paved course. In the interest of time, AMAS was omitted as a test condition so baseline and Smart Cruise could be compared keeping one vehicle as a control as was done previously on the paved road. 


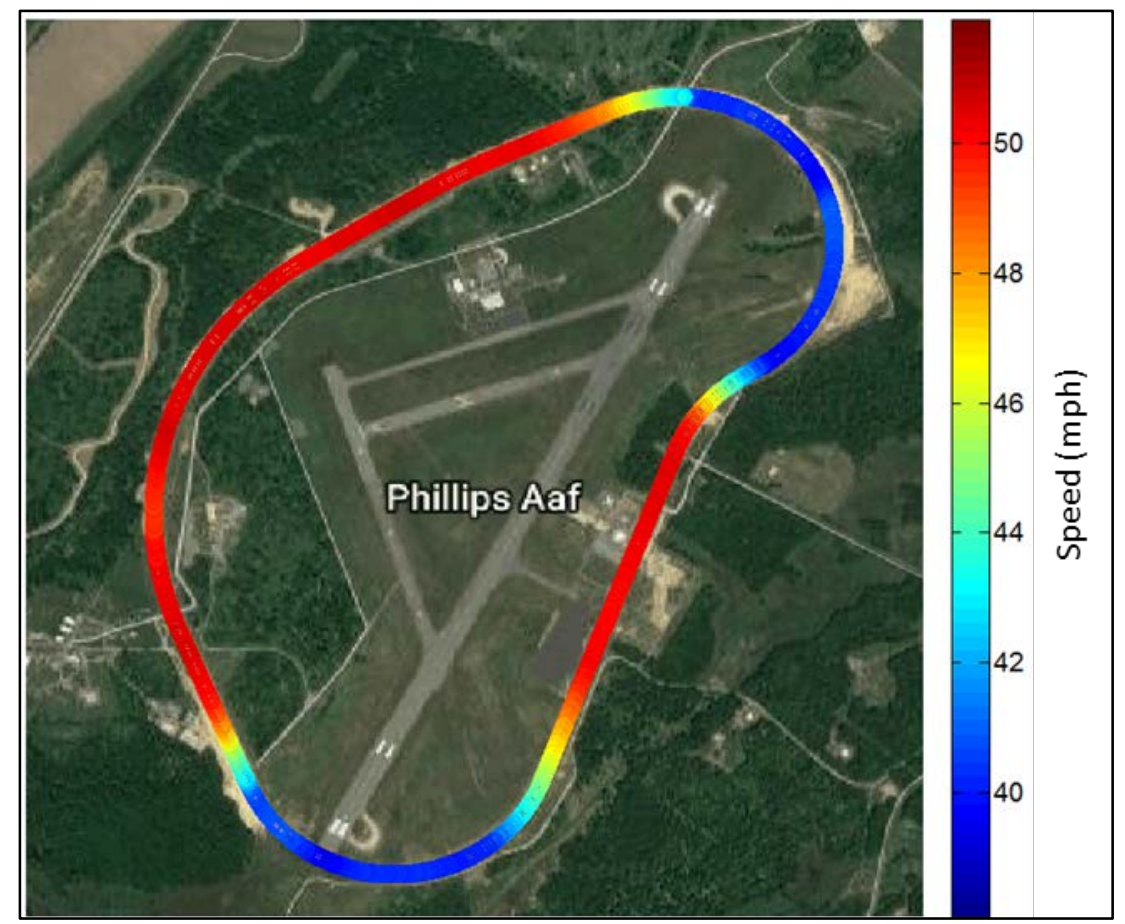

Figure 5. ATEF speed profile (mph)

๑ Google Maps

\begin{tabular}{|c|c|c|c|c|c|c|c|c|c|}
\hline \multicolumn{5}{|c|}{ ATEF (9/21/2016) - Morning } & & & & & \\
\hline & Truck T & $12(\mathrm{A3})$ & Truck T & 13 (A5) & & & & & \\
\hline Lap & Baseline & Test & Baseline & Test & & & & & \\
\hline 1 & Warm-Up & & Warm-Up & & & & & & \\
\hline 2 & Baseline & & Baseline & & & & & & \\
\hline 3 & & 35/45 Man & & 35/45 Man & \multirow{2}{*}{\multicolumn{5}{|c|}{ ATEF (9/21/2016) - Afternoon }} \\
\hline 4 & & 35/45 Man & & 35/45 Man & & & & & \\
\hline 5 & & 35/45 Man & & 35/45 Man & \multirow{2}{*}{\multicolumn{3}{|c|}{ Truck T12 (A3) }} & \multirow{2}{*}{\multicolumn{2}{|c|}{ Truck T13 (A5) }} \\
\hline 6 & & 35/45 Man & & 35/45 Man & & & & & \\
\hline 7 & & 35/45 Man & & 35/45 Man & Lap & Baseline & Test & Baseline & Test \\
\hline 8 & Base Gravel & & Base Gravel & & 1 & Warm-Up & & Warm-Up & \\
\hline 9 & Base Gravel & & Base Gravel & & 2 & Base Gravel & & Base Gravel & \\
\hline 10 & Base Gravel & & Base Gravel & & 3 & Base Gravel & & Base Gravel & \\
\hline 11 & Base Gravel & & Base Gravel & & 4 & Base Gravel & & Base Gravel & \\
\hline 12 & Base Gravel & & Base Gravel & & 5 & Base Gravel & & Base Gravel & \\
\hline 13 & Base Gravel & & & Smart Grav & 6 & & Smart Grav & Base Gravel & \\
\hline 14 & Base Gravel & & & Smart Grav & 7 & & Smart Grav & Base Gravel & \\
\hline 15 & Base Gravel & & & Smart Grav & 8 & & Smart Grav & Base Gravel & \\
\hline 16 & Base Gravel & & & Smart Grav & 9 & & Smart Grav & Base Gravel & \\
\hline 17 & Base Gravel & & & Smart Grav & 10 & & Smart Grav & Base Gravel & \\
\hline
\end{tabular}

Figure 6. ATEF test matrix (9/21/2016)

The third day of testing at ATEF included a condition that was not in the original test matrix, economy mode. Truck T12 (M915A3) was equipped with a transmission control pad button labeled as "MODE," shown in the upper right-hand side of the pad in Figure 7. Enabling this 
feature allowed the transmission to shift into the final top gear, sixth $(0.67: 1)$. Otherwise, the transmission would remain in fifth gear $(0.76: 1)$ even at higher speeds. This feature was not on truck T13 (M915A5), which naturally used all six gears by default.

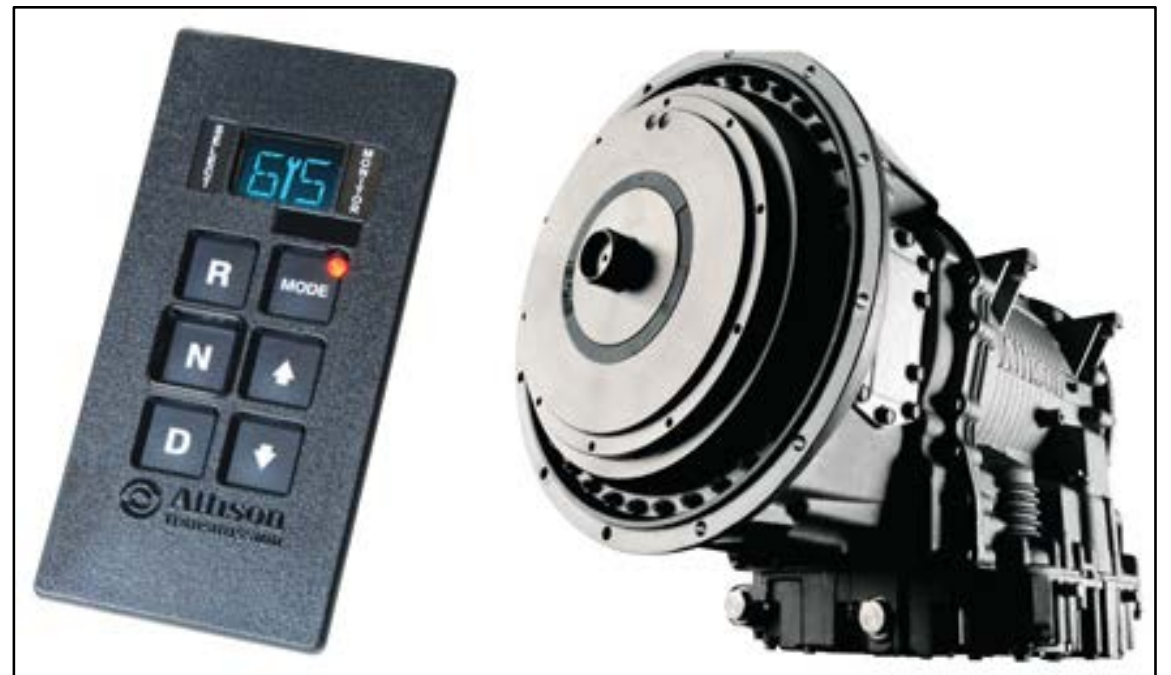

Figure 7. Allison transmission control pad (left) and transmission (right) Photo by Allison Transmission

Because economy mode was not part of the original test plan, it was considered lower priority, and a full control vehicle style test was not performed. However, the team felt it would still be valuable to benchmark the effect while the other vehicle repeated the 35/45-mph manual condition to double-check the previous day's data. This was followed by urban testing, which was performed on the same track with three theoretical stop signs, and a target speed of $25 \mathrm{mph}$. Figure 8 shows a map of the course and the locations of the three theoretical stop signs. Due to the reduced speed, the urban test conditions took approximately twice as long, and therefore, only three laps were completed for each condition. The schedule for day three is shown in Figure 9. All testing was performed on the paved course. 


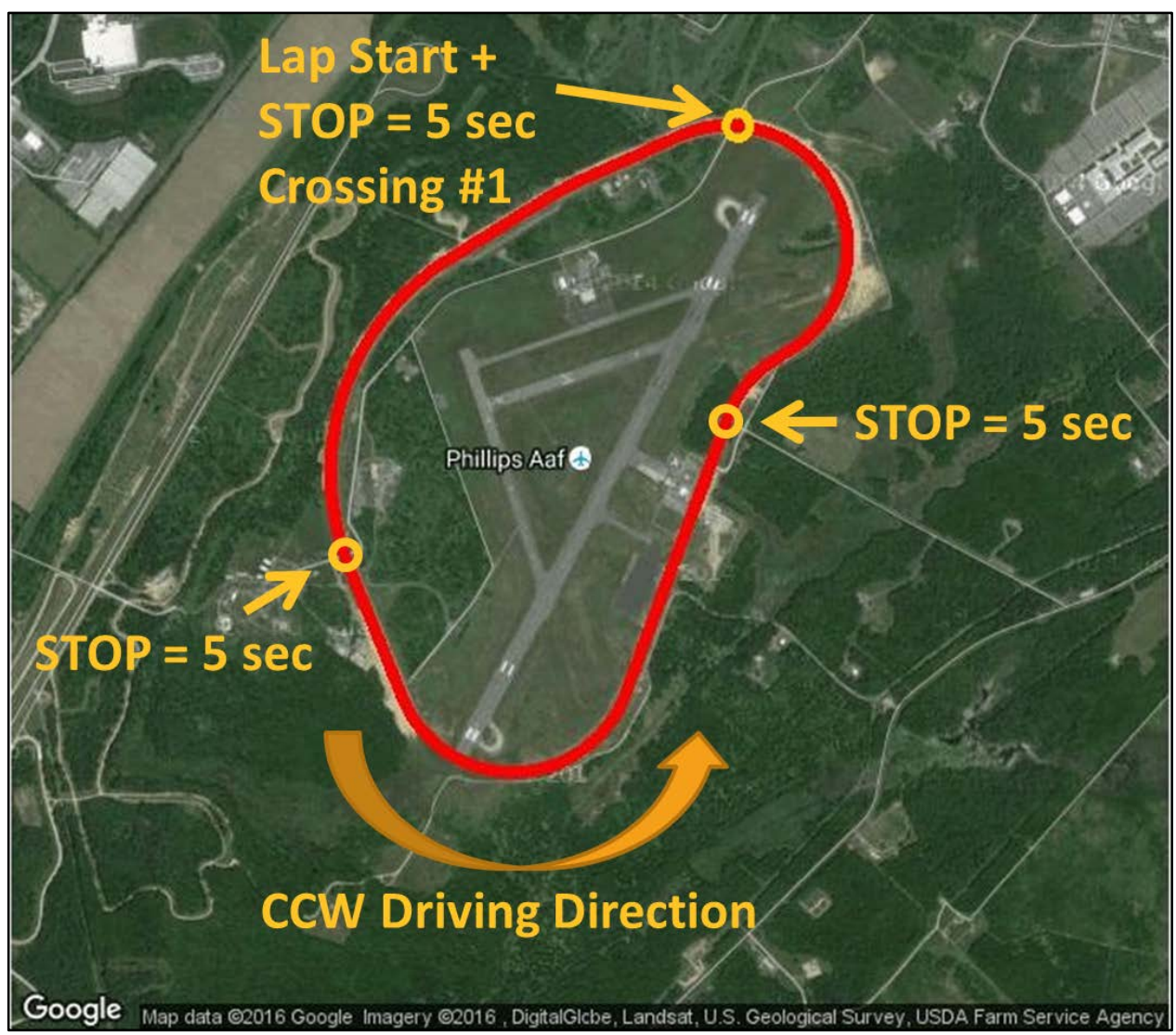

Figure 8. ATEF map, urban

๑ Google Maps

\begin{tabular}{|c|c|c|c|c|}
\hline \multicolumn{5}{|c|}{ ATEF (9/22/2016) } \\
\hline & \multicolumn{2}{|c|}{ Truck T12 (A3) } & \multicolumn{2}{|c|}{ Truck T13 (A5) } \\
\hline Lap & Baseline & Test & Baseline & Test \\
\hline 0 & Warm-Up & & Warm-Up & \\
\hline 1 & Baseline & & Baseline & \\
\hline 2 & Baseline & & Baseline & \\
\hline 3 & Baseline & & Baseline & \\
\hline 4 & Baseline & & Baseline & \\
\hline 5 & Baseline & & Baseline & \\
\hline 6 & & Economy & & 35/45 Man \\
\hline 7 & & Economy & & 35/45 Man \\
\hline 8 & & Economy & & 35/45 Man \\
\hline 9 & & Economy & & 35/45 Man \\
\hline 10 & & Economy & & 35/45 Man \\
\hline 11 & Urban Base & & & Urb Smart \\
\hline 12 & Urban Base & & & Urb Smart \\
\hline 13 & Urban Base & & & Urb Smart \\
\hline 14 & & Urb Smart & Urban Base & \\
\hline 15 & & Urb Smart & Urban Base & \\
\hline 16 & & Urb Smart & Urban Base & \\
\hline
\end{tabular}

Figure 9. ATEF test matrix (9/22/2016) 


\section{Churchville Test Area (CTA)}

The CTA spans over 250 acres with 11 miles of interconnecting roads and test courses. It has a number of hilly cross-country courses with steep grades as well as controlled surfaces including mud, dust, and gravel. Test Course $\mathrm{C}$, used for this testing, was wetted ahead of testing for dust control. The course is roughly 2.4 miles round trip, with a turnaround loop on either end. Figure 10 shows a map of the course, the four stop locations, and the geofence area used to split the laps. Unlike ATEF, at CTA the vehicles came to a complete stop between laps.

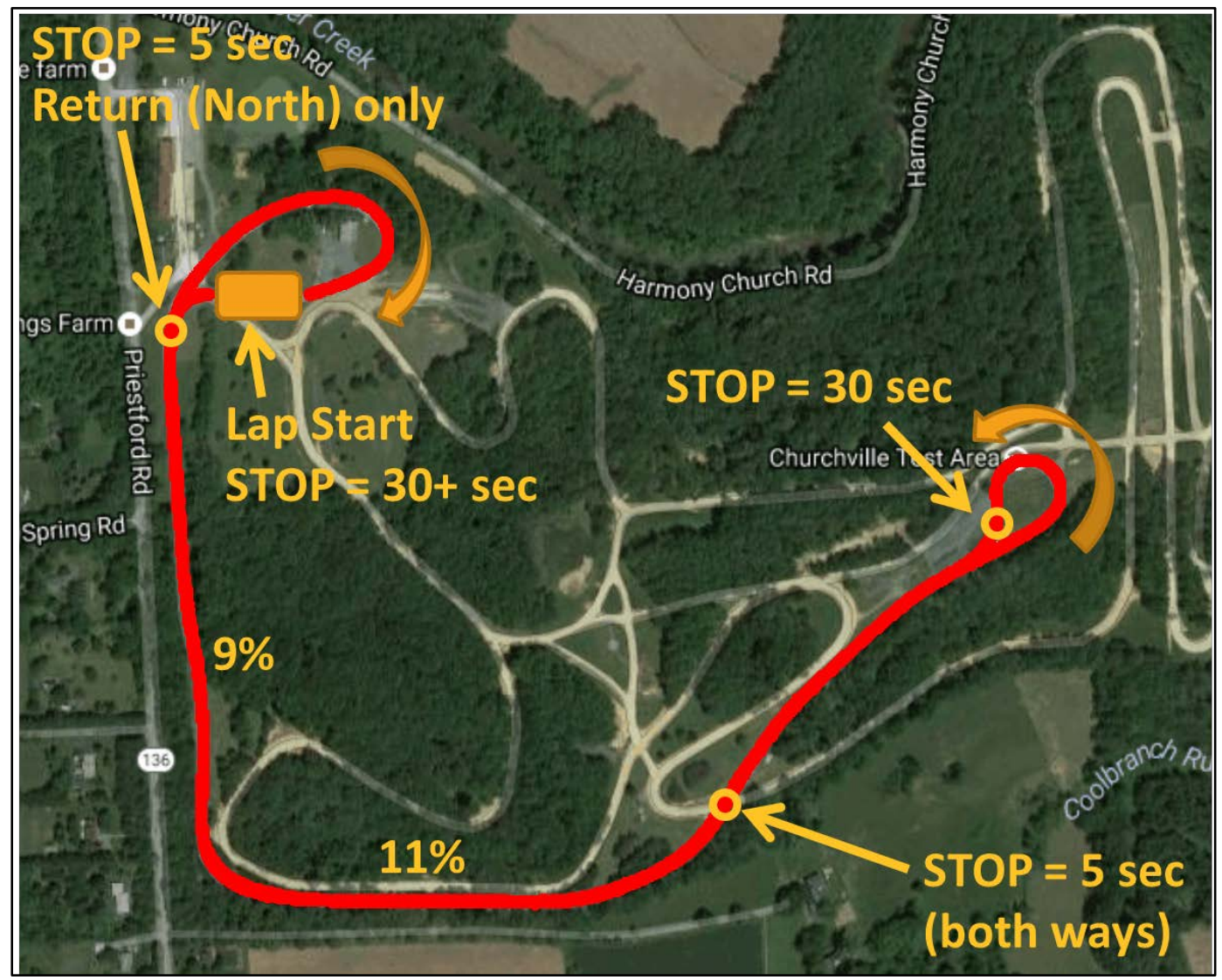

Figure 10. CTA map, Course C

๑ Google Maps

The test schedule for CTA Course C is shown in Figure 11. Example speed, fueling, and road grade traces are shown in Figure 12 for the baseline condition. Grade was calculated from the Garmin GPS using the velocity component data (east, north and up). The trace data show a large portion of the fueling is driven by uphill grade events on this test course. 


\begin{tabular}{|c|c|c|c|c|}
\hline \multicolumn{5}{|c|}{ CTA - C Course $(9 / 23 / 2016)$} \\
\hline & \multicolumn{2}{|c|}{ Truck T12 (A3) } & \multicolumn{2}{|c|}{ Truck T13 (A5) } \\
\hline Lap & Baseline & Test & Baseline & Test \\
\hline 1 & Warm-Up & & Warm-Up & \\
\hline 2 & Warm-Up & & Warm-Up & \\
\hline 3 & Warm-Up & & Warm-Up & \\
\hline 4 & Baseline & & Baseline & \\
\hline 5 & Baseline & & Baseline & \\
\hline 6 & Baseline & & Baseline & \\
\hline 7 & & Smart & Baseline & \\
\hline 8 & & Smart & Baseline & \\
\hline 9 & & Smart & Baseline & \\
\hline 10 & Baseline & & & Smart \\
\hline 11 & Baseline & & & Smart \\
\hline 12 & Baseline & & & Smart \\
\hline 13 & & AMAS & & AMAS \\
\hline 14 & & AMAS & & AMAS \\
\hline 15 & & AMAS & & AMAS \\
\hline
\end{tabular}

Figure 11. CTA - C course test matrix (9/23/2016)
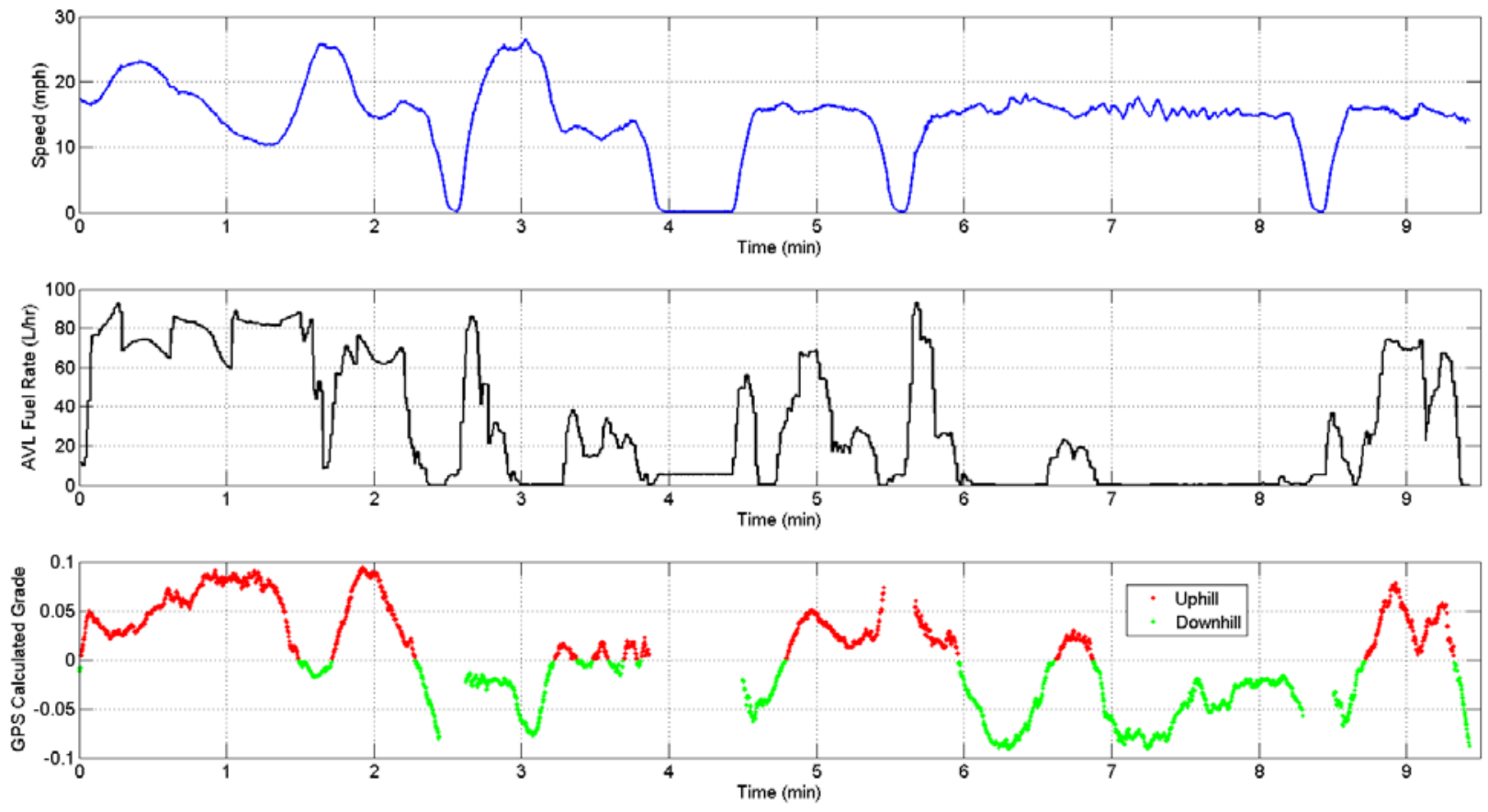

Figure 12. Speed, fueling, and grade traces 


\section{Munson Test Area (MTA)}

The MTA maintains a number of specific surfaces and obstacles for vehicle testing. For the fuel economy testing performed here, sections of the paved course, improved gravel, and the $15 \%$ grade slope were used. As at the ATEF, the vehicles ran all laps for each condition sequentially, entering each lap at speed. The geo-marker for lap start was used to splice the data for individual laps. Figure 13 shows a map of the course, lap start, and clockwise direction of travel for all laps.

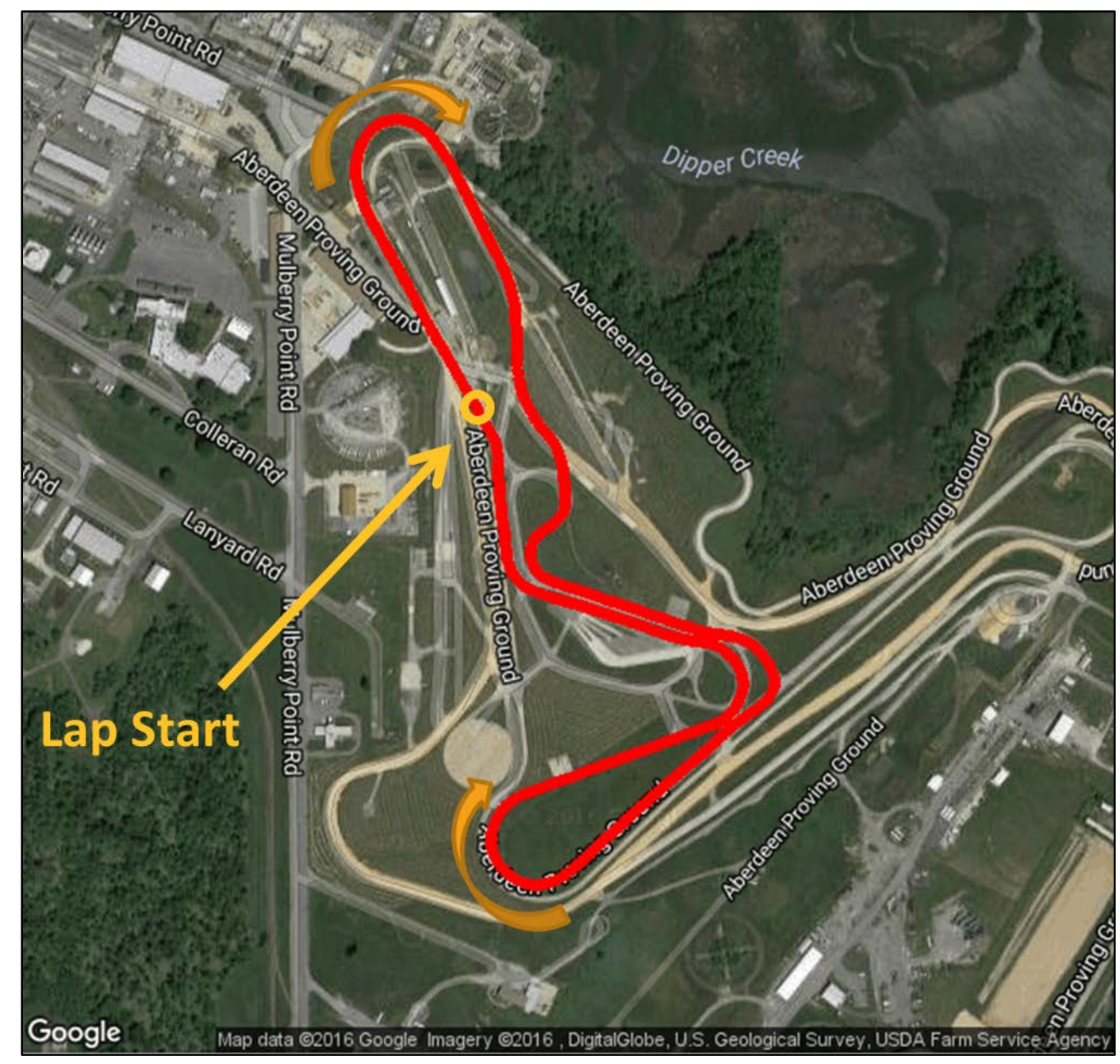

Figure 13. MTA map, fuel consumption course

๑ Google Maps

The test schedule for MTA is shown in Figure 14. The morning and afternoon test schedules are exactly the same. The AVL fuel flow meter was not properly configured on truck T13 (M915A5) during the morning tests so the tests were repeated in the afternoon by both vehicles. All testing at MTA was performed in manual / baseline mode at three different target speeds for comparison with previous benchmark testing. 


\begin{tabular}{|c|c|c|c|c|c|}
\hline \multicolumn{3}{|c|}{ MTA - (10/4/2016) AM } & \multicolumn{3}{|c|}{ MTA - (10/4/2016) PM } \\
\hline Lap & Truck T12 (A3) & Truck T13 (A5) & Lap & Truck T12 (A3) & Truck T13 (A5) \\
\hline 1 & Warm-Up & Warm-Up & 1 & Warm-Up & Warm-Up \\
\hline 2 & $10 \mathrm{mph}$ & $10 \mathrm{mph}$ & 2 & $10 \mathrm{mph}$ & $10 \mathrm{mph}$ \\
\hline 3 & $10 \mathrm{mph}$ & $10 \mathrm{mph}$ & 3 & $10 \mathrm{mph}$ & $10 \mathrm{mph}$ \\
\hline 4 & $10 \mathrm{mph}$ & $10 \mathrm{mph}$ & 4 & $10 \mathrm{mph}$ & $10 \mathrm{mph}$ \\
\hline 5 & $10 \mathrm{mph}$ & $10 \mathrm{mph}$ & 5 & $10 \mathrm{mph}$ & $10 \mathrm{mph}$ \\
\hline 6 & $10 \mathrm{mph}$ & $10 \mathrm{mph}$ & 6 & $10 \mathrm{mph}$ & $10 \mathrm{mph}$ \\
\hline 7 & $15 \mathrm{mph}$ & $15 \mathrm{mph}$ & 7 & $15 \mathrm{mph}$ & $15 \mathrm{mph}$ \\
\hline 8 & $15 \mathrm{mph}$ & $15 \mathrm{mph}$ & 8 & $15 \mathrm{mph}$ & $15 \mathrm{mph}$ \\
\hline 9 & $15 \mathrm{mph}$ & $15 \mathrm{mph}$ & 9 & $15 \mathrm{mph}$ & $15 \mathrm{mph}$ \\
\hline 10 & $15 \mathrm{mph}$ & $15 \mathrm{mph}$ & 10 & $15 \mathrm{mph}$ & $15 \mathrm{mph}$ \\
\hline 11 & $15 \mathrm{mph}$ & $15 \mathrm{mph}$ & 11 & $15 \mathrm{mph}$ & $15 \mathrm{mph}$ \\
\hline 12 & $20 \mathrm{mph}$ & $20 \mathrm{mph}$ & 12 & $20 \mathrm{mph}$ & $20 \mathrm{mph}$ \\
\hline 13 & $20 \mathrm{mph}$ & $20 \mathrm{mph}$ & 13 & $20 \mathrm{mph}$ & $20 \mathrm{mph}$ \\
\hline 14 & $20 \mathrm{mph}$ & $20 \mathrm{mph}$ & 14 & $20 \mathrm{mph}$ & $20 \mathrm{mph}$ \\
\hline 15 & $20 \mathrm{mph}$ & $20 \mathrm{mph}$ & 15 & $20 \mathrm{mph}$ & $20 \mathrm{mph}$ \\
\hline 16 & $20 \mathrm{mph}$ & $20 \mathrm{mph}$ & 16 & $20 \mathrm{mph}$ & $20 \mathrm{mph}$ \\
\hline
\end{tabular}

Figure 14. MTA fuel course test matrix (10/4/2016)

\section{Perryman Test Area (PTA)}

PTA Course 1 is a roughly 5-mile-long cross-country loop. Laps were again run sequentially using the lap start geo-marker to parse individual laps. Figure 15 shows a map of the course, lap start, and counterclockwise direction of travel for all laps. 


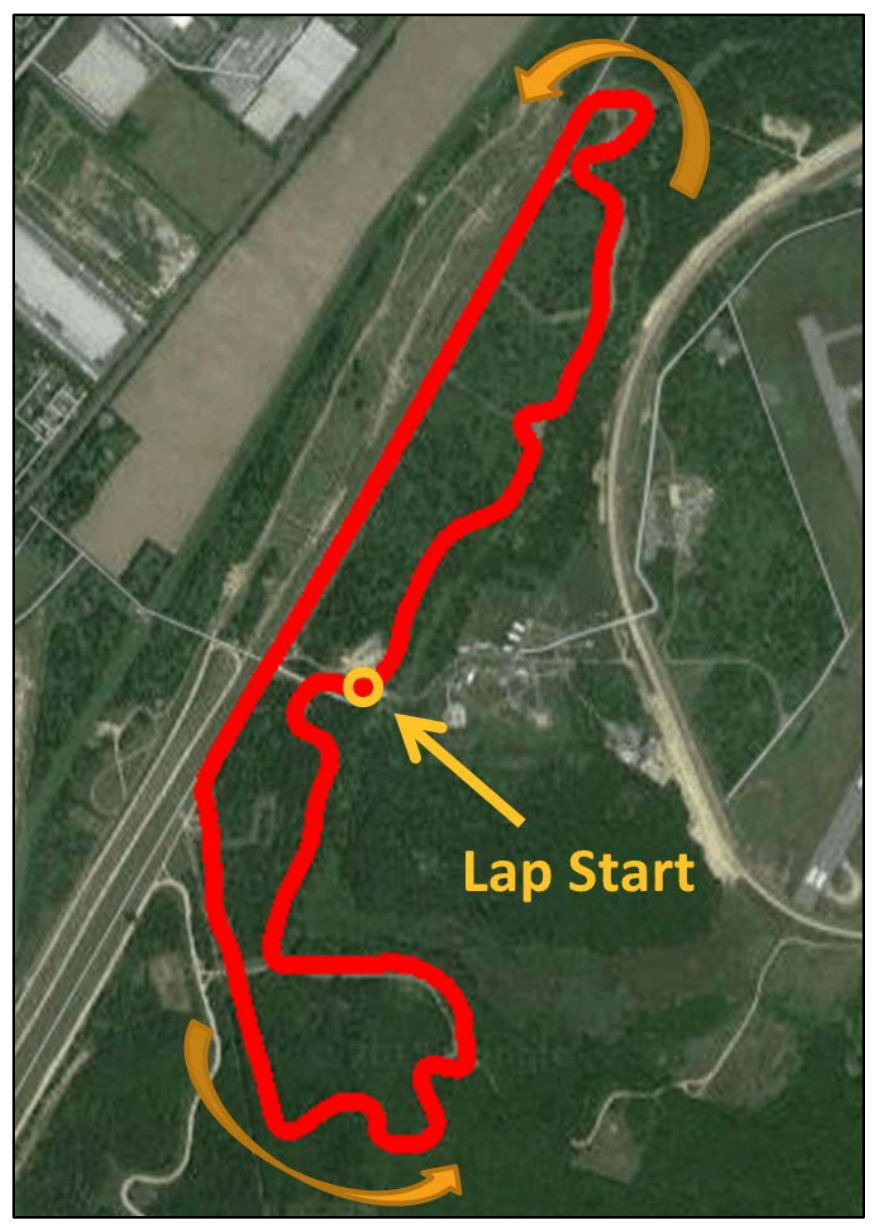

Figure 15. PTA map, Course 1

( ) Google Maps

The test schedule for PTA is shown in Figure 16. Just like MTA, all testing was performed in manual / baseline mode for comparison with previous benchmark testing.

\begin{tabular}{|c|c|c|}
\hline \multicolumn{3}{|c|}{ PTA - (10/12/2016) } \\
\hline Lap & Truck T12 (A3) & Truck T13 (A5) \\
\hline 1 & Warm-Up & Warm-Up \\
\hline 2 & Course 1 & Course 1 \\
\hline 3 & Course 1 & Course 1 \\
\hline 4 & Course 1 & Course 1 \\
\hline
\end{tabular}

Figure 16. PTA test matrix (10/12/2016) 


\section{Results}

Fuel consumption was calculated for each valid test lap using both the high-accuracy AVL KMA mobile unit and the integrated CAN-reported fuel rate from the engine for comparison. Various other lap statistics were also calculated to ensure run-to-run repeatability. These statistics included lap, time, distance, average speed, fuel use, average fuel density, average coolant temperature, average oil temperature, average transmission temperature, median engine speed, and total engine work. The raw fuel consumption numbers from the control and test vehicle for each lap were then entered into the SAE J1321-supplied data analysis worksheet to compute fuel saved and fuel economy improvement with corresponding 95\% confidence intervals. An example is shown in Figure 17 for truck T12 (M915A3) comparing Smart cruise to the manual / baseline condition on ATEF-paved, using the CAN-reported fuel values.

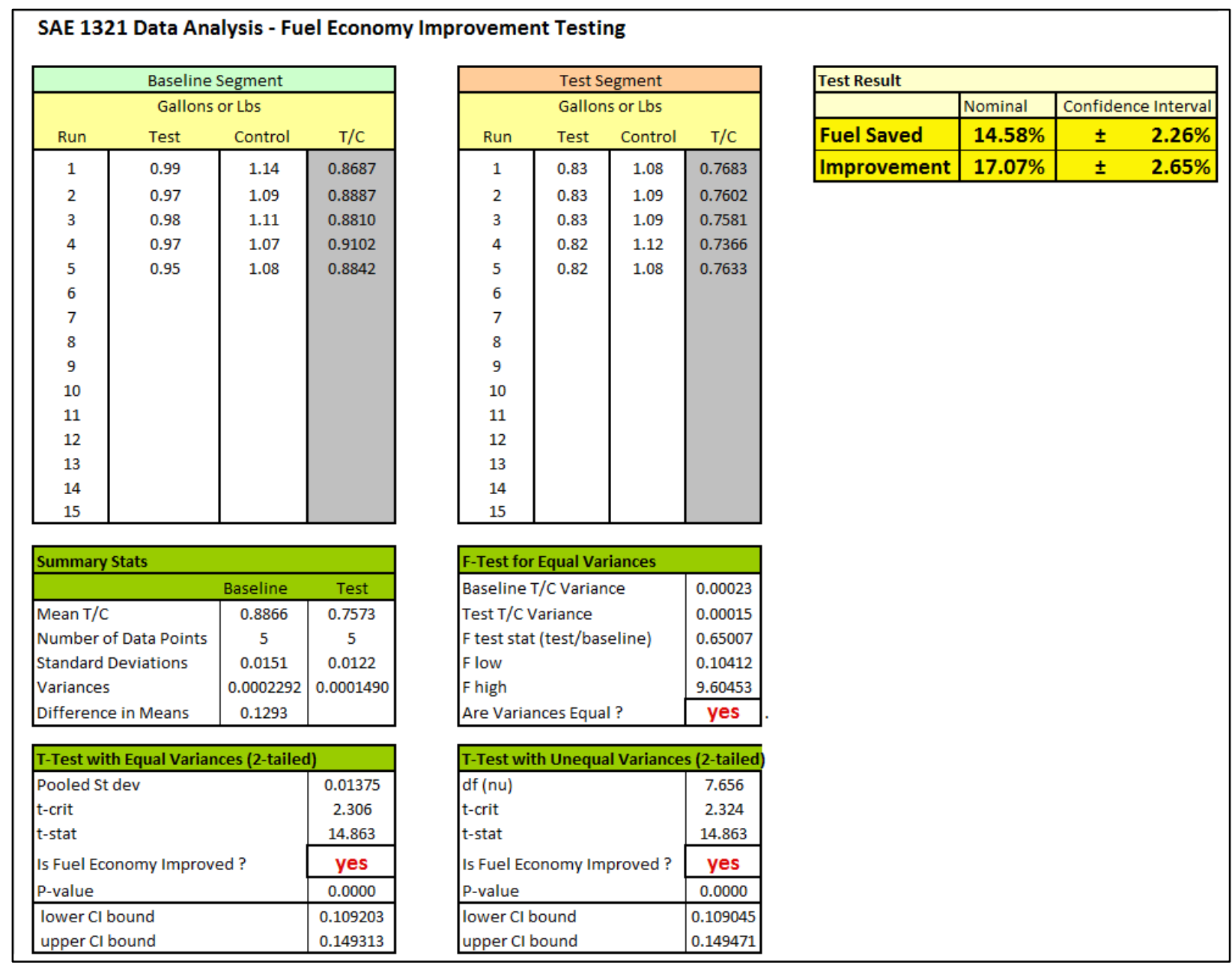

Figure 17. SAE J1321-supplied worksheet example

A high-level overview of the various test courses, target speeds, and modes of operation tested is shown in Table 3. All the SAE J1321 worksheet comparison results are summarized in Table 4. Red values indicate the fuel consumption got worse or increased, a gray background indicates data are not available, and gray text indicates the data were valid but the solution was not statically significant and therefore neither a benefit nor a disadvantage can be claimed. The 
major component of the reference to test case comparison has been highlighted in yellow for ease of identification. Note that the example in Figure 17 corresponds to the third row of Table 4.

Table 3. ATC Test Course Overview

\begin{tabular}{llll}
\hline Course & Lap Dist. (mi) & Speeds (mph) & Modes \\
\hline ATEF Paved & 4.5 & 50 straights, 40 turns & Manual, AMAS, Smart \\
ATEF Paved & 4.5 & 50 straights, 40 turns & Economy (T12 only) \\
ATEF Paved & 4.5 & 45 straights, 35 turns & Manual \\
ATEF Gravel & 4.5 & 50 straights, 40 turns & Manual, Smart \\
ATEF Paved (Urban) & 4.5 & 25 with three stops & Manual, Smart \\
Churchville C & 2.4 & 25 with four stops & Manual, AMAS, Smart \\
Munson Fuel Course (15\% Grade) & 1.5 & $10,15,20$ & Manual \\
Perryman Course 1 & 5.0 & 30 & Manual \\
\hline
\end{tabular}

Table 4. SAE J1321 Results Summary

\begin{tabular}{|c|c|c|c|c|c|c|}
\hline & & & Fuel & aved & FE (mpg) II & provement \\
\hline & & & CAN Based & AVL Based & CAN Based & AVL Based \\
\hline Truck & Reference & Test Case & Nominal $\pm \mathrm{Cl}$ & Nominal $\pm \mathrm{Cl}$ & Nominal $\pm \mathrm{Cl}$ & Nominal $\pm \mathrm{Cl}$ \\
\hline T12 (A3) & 40/50 Manual Paved & 40/50 AMAS Paved & $-4.3 \% \pm 3.7 \%$ & N/A & $-4.2 \% \pm 3.5 \%$ & N/A \\
\hline T13 (A5) & 40/50 Manual Paved & 40/50 AMAS Paved & $-2.9 \% \pm 2.4 \%$ & $-2.7 \% \pm 2.2 \%$ & $-2.8 \% \pm 2.3 \%$ & $-2.6 \% \pm 2.1 \%$ \\
\hline T12 (A3) & 40/50 Manual Paved & Smart Cruise Paved & $14.6 \% \pm 2.3 \%$ & N/A & $17.1 \% \pm 2.6 \%$ & N/A \\
\hline T13 (A5) & 40/50 Manual Paved & Smart Cruise Paved & $13.8 \% \pm 3.0 \%$ & $12.9 \% \pm 4.3 \%$ & $16.0 \% \pm 3.4 \%$ & $14.9 \% \pm 4.9 \%$ \\
\hline T12 (A3) & 40/50 Manual Paved & 35/45 Manual Paved & $12.1 \% \pm 2.7 \%$ & $11.5 \% \pm 2.8 \%$ & $13.8 \% \pm 3.0 \%$ & $12.9 \% \pm 3.2 \%$ \\
\hline T13 (A5) & 40/50 Manual Paved & 35/45 Manual Paved & $10.9 \% \pm 2.6 \%$ & $8.3 \% \pm 2.1 \%$ & $12.2 \% \pm 2.9 \%$ & $9.1 \% \pm 2.2 \%$ \\
\hline T12 (A3) & 40/50 Manual Paved & 40/50 Manual Gravel & $-39.4 \% \pm 4.1 \%$ & $-36.8 \% \pm 2.4 \%$ & $-28.3 \% \pm 2.9 \%$ & $-26.9 \% \pm 1.7 \%$ \\
\hline T13 (A5) & 40/50 Manual Paved & 40/50 Manual Gravel & $-50.1 \% \pm 3.1 \%$ & $-48.8 \% \pm 4.0 \%$ & $-33.4 \% \pm 2.1 \%$ & $-32.8 \% \pm 2.7 \%$ \\
\hline T12 (A3) & 40/50 Manual Gravel & Smart Cruise Gravel & $4.3 \% \pm 3.0 \%$ & $3.3 \% \pm 2.8 \%$ & $4.5 \% \pm 3.1 \%$ & $3.4 \% \pm 2.9 \%$ \\
\hline T13 (A5) & 40/50 Manual Gravel & Smart Cruise Gravel & $8.3 \% \pm 2.6 \%$ & $4.8 \% \pm 4.6 \%$ & $9.1 \% \pm 2.8 \%$ & $5.1 \% \pm 4.9 \%$ \\
\hline T12 (A3) & Urban Manual Paved & Urban Smart Paved & $-4.0 \% \pm 2.3 \%$ & $-1.4 \% \pm 2.6 \%$ & $-3.8 \% \pm 2.2 \%$ & $-1.4 \% \pm 2.6 \%$ \\
\hline T13 (A5) & Urban Manual Paved & Urban Smart Paved & $0.1 \% \pm 3.1 \%$ & $0.7 \% \pm 1.4 \%$ & $0.1 \% \pm 3.1 \%$ & $0.7 \% \pm 1.4 \%$ \\
\hline T12 (A3) & 40/50 Manual Paved & $\begin{array}{c}\text { 40/50 Economy } \\
\text { Paved }\end{array}$ & $7.7 \% \pm 1.6 \%$ & $7.3 \% \pm 1.4 \%$ & $8.3 \% \pm 1.7 \%$ & $7.9 \% \pm 1.5 \%$ \\
\hline T12 (A3) & CTA-C Manual & CTA-C Smart & $-19.0 \% \pm 3.0 \%$ & $-20.0 \% \pm 2.9 \%$ & $-15.9 \% \pm 2.5 \%$ & $-16.7 \% \pm 2.4 \%$ \\
\hline T13 (A5) & CTA-C Manual & CTA-C Smart & $-15.0 \% \pm 4.6 \%$ & $-13.8 \% \pm 3.8 \%$ & $-13.1 \% \pm 4.0 \%$ & $-12.1 \% \pm 3.3 \%$ \\
\hline T12 (A3) & CTA-C Manual & CTA-C AMAS & $-13.8 \% \pm 2.6 \%$ & $-17.9 \% \pm 2.5 \%$ & $-12.1 \% \pm 2.3 \%$ & $-15.2 \% \pm 2.1 \%$ \\
\hline T13 (A5) & CTA-C Manual & CTA-C AMAS & $-10.5 \% \pm 19.9 \%$ & $-13.3 \% \pm 17.7 \%$ & $-9.5 \% \pm 18.0 \%$ & $-11.7 \% \pm 15.6 \%$ \\
\hline
\end{tabular}

$\mathrm{Cl}=95 \%$ confidence interval

The MTA and PTA test runs were not intended for a fuel consumption improvement calculation, but rather to benchmark the fuel economy in manual mode for comparison against legacy testing. Table 5 shows summary statistics for each unique test condition and vehicle. Each row represents an average of all valid runs at that condition. Fuel economy was calculated using the AVL KMA mobile fuel flow results. 
Table 5. Averages for Each Test Condition

\begin{tabular}{|c|c|c|c|c|c|c|c|c|c|c|c|c|c|c|}
\hline & Truck & 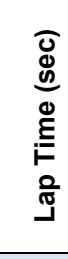 & 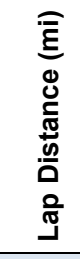 & 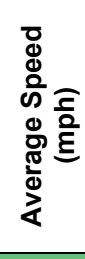 & 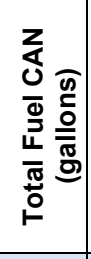 & 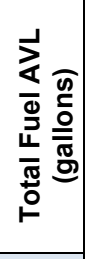 & 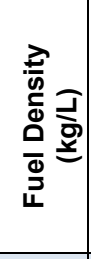 & 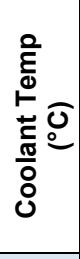 & 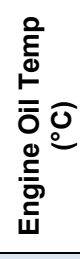 & 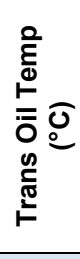 & 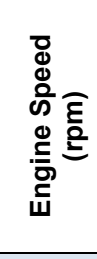 & 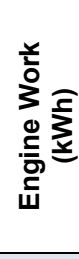 & 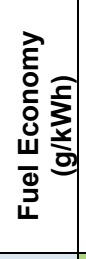 & 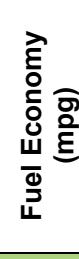 \\
\hline Baseline & T12 (A3) & 355 & 4.53 & 45.9 & 0.96 & 1.03 & 0.82 & 87 & 89 & 91 & 1,491 & 15.1 & 213 & 4.38 \\
\hline Economy & T12 (A3) & 354 & 4.53 & 46.1 & 0.89 & 0.96 & 0.82 & 87 & 88 & 91 & 1,381 & 14.3 & 209 & 4.71 \\
\hline Baseline & T13 (A5) & 354 & 4.53 & 46.0 & 1.09 & 1.09 & 0.82 & 80 & 81 & 93 & 1,512 & 15.6 & 217 & 4.16 \\
\hline AMAS Cruise & T12 (A3) & 354 & 4.53 & 46.0 & 1.00 & & 0.82 & 87 & 89 & 91 & 1,468 & 16.1 & & 4.55 \\
\hline AMAS Cruise & T13 (A5) & 350 & 4.53 & 46.6 & 1.08 & 1.09 & 0.82 & 80 & 81 & 92 & 1,472 & 16.2 & 209 & 4.15 \\
\hline Smart Cruise & T12 (A3) & 398 & 4.53 & 41.0 & 0.83 & & 0.82 & 87 & 88 & 90 & 1,318 & 13.8 & & 5.48 \\
\hline Smart Cruise & T13 (A5) & 398 & 4.52 & 40.9 & 0.92 & 0.94 & 0.82 & 80 & 80 & 91 & 1,431 & 13.1 & 220 & 4.84 \\
\hline 35/45 Manual & $\mathrm{T} 12$ (A3) & 398 & 4.53 & 41.0 & 0.85 & 0.92 & 0.83 & 86 & 88 & 90 & 1,339 & 13.3 & 217 & 4.91 \\
\hline 35/45 Manual & T13 (A5) & 398 & 4.53 & 40.9 & 0.99 & 1.01 & 0.82 & 80 & 81 & 91 & 1,443 & 13.9 & 226 & 4.49 \\
\hline Baseline Gravel & T12 (A3) & 362 & 4.57 & 45.5 & 1.31 & 1.39 & 0.82 & 91 & 92 & 94 & 1,509 & 22.0 & 196 & 3.29 \\
\hline Baseline Gravel & T13 (A5) & 364 & 4.57 & 45.2 & 1.56 & 1.56 & 0.82 & 83 & 85 & 96 & 1,531 & 23.0 & 210 & 2.93 \\
\hline Smart Cruise Gravel & T12 (A3) & 411 & 4.57 & 40.0 & 1.19 & 1.29 & 0.81 & 91 & 93 & 95 & 1,390 & 20.0 & 198 & 3.54 \\
\hline Smart Cruise Gravel & T13 (A5) & 402 & 4.57 & 40.9 & 1.45 & 1.50 & 0.82 & 82 & 84 & 92 & 1,423 & 21.4 & 217 & 3.05 \\
\hline Urban Baseline & T12 (A3) & 705 & 4.53 & 23.1 & 0.91 & 1.05 & 0.82 & 90 & 91 & 94 & 1,512 & 13.0 & 252 & 4.30 \\
\hline Urban Baseline & T13 (A5) & 700 & 4.53 & 23.3 & 1.03 & 1.04 & 0.82 & 81 & 83 & 96 & 1,148 & 14.1 & 227 & 4.37 \\
\hline Urban Smart Cruise & T12 (A3) & 687 & 4.53 & 23.7 & 0.95 & 1.07 & 0.82 & 89 & 91 & 93 & 1,417 & 13.9 & 238 & 4.24 \\
\hline Urban Smart Cruise & T13 (A5) & 697 & 4.53 & 23.4 & 1.02 & 1.03 & 0.82 & 81 & 82 & 95 & 1,170 & 14.1 & 225 & 4.40 \\
\hline CTA - C Baseline & T12 (A3) & 565 & 2.23 & 14.2 & 1.14 & 1.23 & 0.82 & 92 & 94 & 98 & 1,355 & 18.3 & 210 & 1.80 \\
\hline CTA - C Baseline & T13 (A5) & 561 & 2.24 & 14.3 & 1.34 & 1.34 & 0.82 & 88 & 90 & 99 & 1,388 & 19.2 & 218 & 1.67 \\
\hline CTA - C Smart & T12 (A3) & 740 & 2.22 & 10.8 & 1.34 & 1.46 & 0.82 & 93 & 95 & 100 & 1,274 & 21.5 & 211 & 1.52 \\
\hline CTA - C Smart & T13 (A5) & 750 & 2.22 & 10.7 & 1.56 & 1.57 & 0.82 & 91 & 94 & 102 & 1,284 & 23.4 & 207 & 1.42 \\
\hline CTA-C AMAS & T12 (A3) & 609 & 2.22 & 13.1 & 1.30 & 1.44 & 0.81 & 93 & 95 & 100 & 1,352 & 21.5 & 207 & 1.54 \\
\hline CTA - C AMAS & T13 (A5) & 601 & 2.23 & 13.4 & 1.49 & 1.53 & 0.81 & 91 & 95 & 102 & 1,380 & 22.8 & 206 & 1.47 \\
\hline MTA - $10 \mathrm{mph}$ & T12 (A3) & 528 & 1.52 & 10.4 & 0.57 & 0.61 & 0.82 & 92 & 92 & 98 & 1,043 & 8.3 & 228 & 2.50 \\
\hline MTA-10 mph & T13 (A5) & 545 & 1.53 & 10.1 & 0.69 & 0.67 & 0.82 & 86 & 87 & 99 & 1,099 & 9.6 & 217 & 2.23 \\
\hline MTA-15 mph & T12 (A3) & 366 & 1.52 & 15.0 & 0.48 & 0.54 & 0.82 & 92 & 93 & 96 & 1,398 & 7.4 & 226 & 2.82 \\
\hline MTA-15 mph & T13 (A5) & 372 & 1.52 & 14.8 & 0.60 & 0.61 & 0.82 & 85 & 89 & 95 & 1,469 & 8.3 & 227 & 2.50 \\
\hline MTA-20 mph & T12 (A3) & 281 & 1.52 & 19.5 & 0.45 & 0.50 & 0.82 & 92 & 93 & 97 & 1,391 & 7.1 & 217 & 3.05 \\
\hline MTA- $20 \mathrm{mph}$ & T13 (A5) & 284 & 1.52 & 19.3 & 0.63 & 0.64 & 0.82 & 85 & 87 & 99 & 1,507 & 9.1 & 217 & 2.41 \\
\hline PTA - Course 1 & T12 (A3) & 622 & 4.98 & 28.8 & 1.47 & 1.59 & 0.83 & 90 & 91 & 95 & 1,370 & 23.2 & 215 & 3.13 \\
\hline PTA - Course 1 & T13 (A5) & 621 & 4.97 & 28.8 & 1.79 & 1.80 & 0.83 & 85 & 87 & 96 & 1,387 & 25.6 & 220 & 2.76 \\
\hline
\end{tabular}

A subset of these results is also shown graphically in Figure 18. The plot on the left shows the relationship between fuel economy and total fuel use grouped by test area. Truck T13 (A5) 
generally had higher fuel use and lower fuel economy due to its lower gearing and higher test weight. The plot on the right shows the relatively tight relationship between the total mass of fuel used and the total CAN-reported engine work. The slope of the fit curve represents the average brake specific fuel consumption across all test conditions, $\sim 212 \mathrm{~g} / \mathrm{kWh}$. This is equivalent to roughly $39.4 \%$ thermal efficiency, assuming diesel has a lower net heating value of $43 \mathrm{MJ} / \mathrm{kg}$. Looking at specific test cases in the table shows that conditions with higher than average brake specific fuel consumption include low-speed, light-load conditions such as ATEF - Urban. Test cases with the lowest brake specific fuel consumption and highest efficiency include high-load conditions such as ATEF - Gravel.

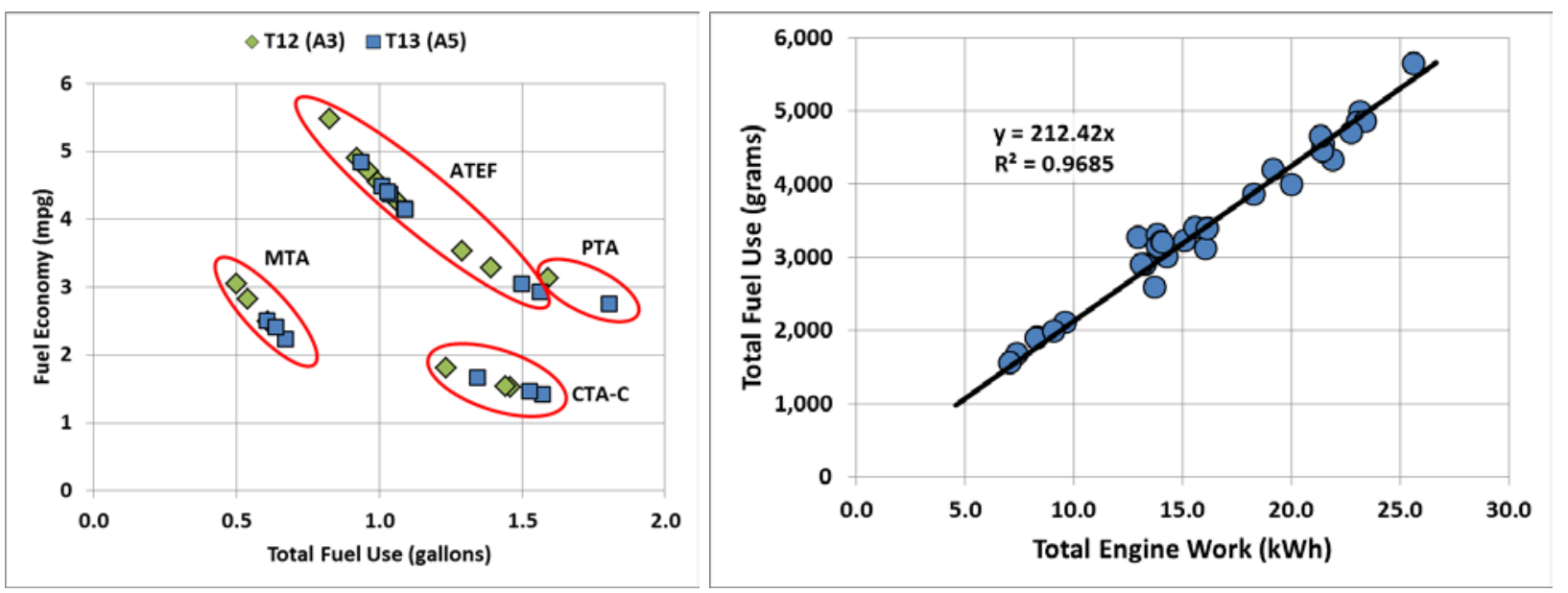

Figure 18. Fuel use trends

A graphical comparison of the fuel savings from the various modes of operation is shown in Figure 19. The AMAS Cruise mode did not demonstrate a benefit over manual drivers under any conditions. The Smart Cruise system showed promising results on ATEF, but requires further refinement for hilly conditions such as CTA Course C. 


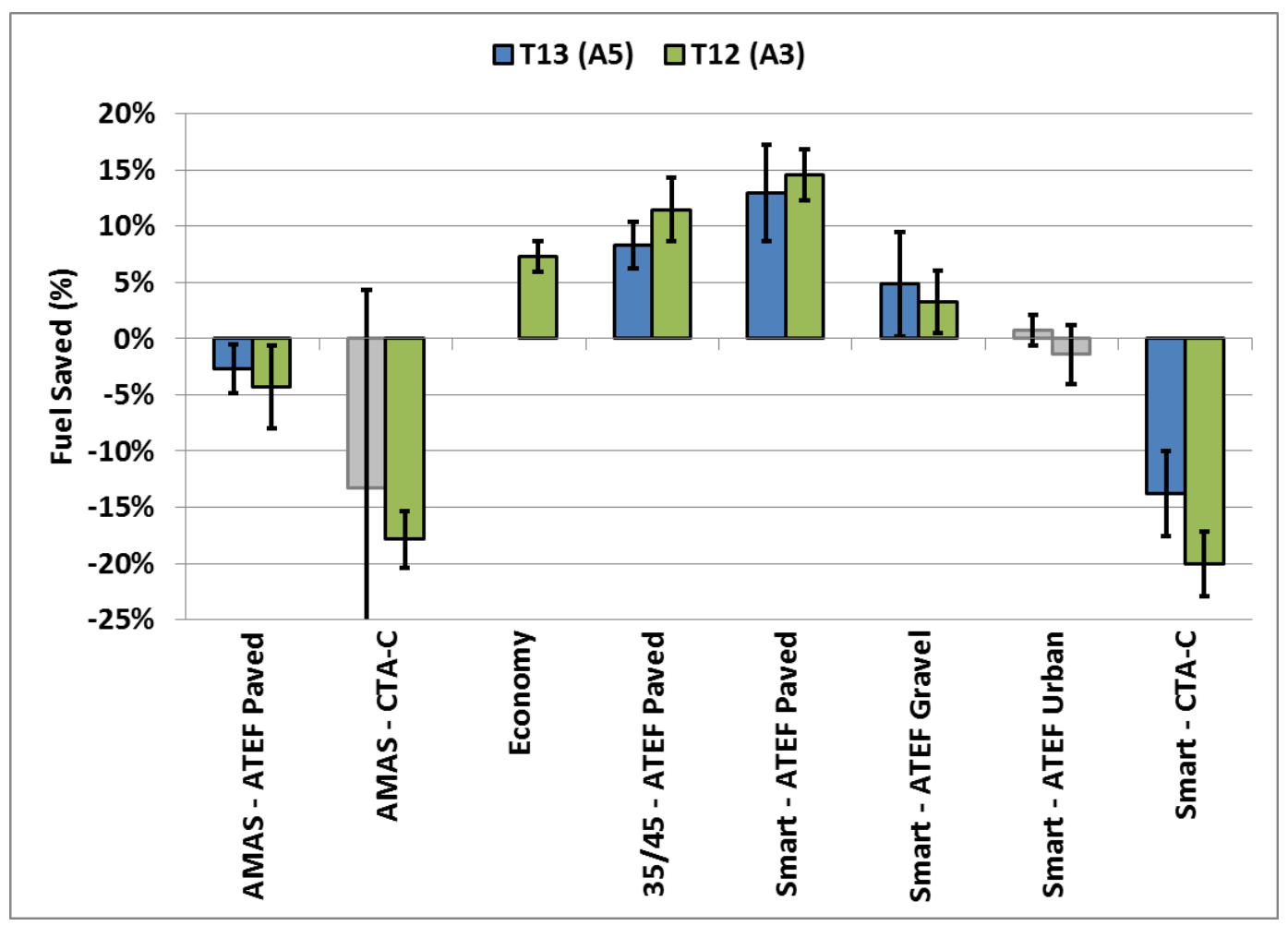

Figure 19. Fuel savings from various modes of operation

\section{Additional Analysis}

Beyond the bulk lap statistics presented in the previous section, a wealth of time series $10-\mathrm{Hz}$ data was collected and made available to the group. These data can be used to dive into specific test cases and identify areas for improvement. Although not the focus of this report, a sampling of the possible data products that can be derived from this data is presented below. The left graph in Figure 20 shows all points of operation for truck T13 (M915A5) from all test runs combined with the J1939 broadcast torque curve in red. The right graph in Figure 20 is a smoothed surface fit of engine fuel rate. Such a map could be used as a lookup to better estimate fuel consumption under various operating conditions when trying to make a model-based decision on where to operate the vehicle. Figure 21 shows a simple example of how laying data on top of a course map can help better understand what is going on in certain sections. This example clearly shows the aggressive fueling to accelerate the vehicle out of the turns and upshift as the vehicle reaches speed. The lack of fueling and downshift going into the turns are also shown. 

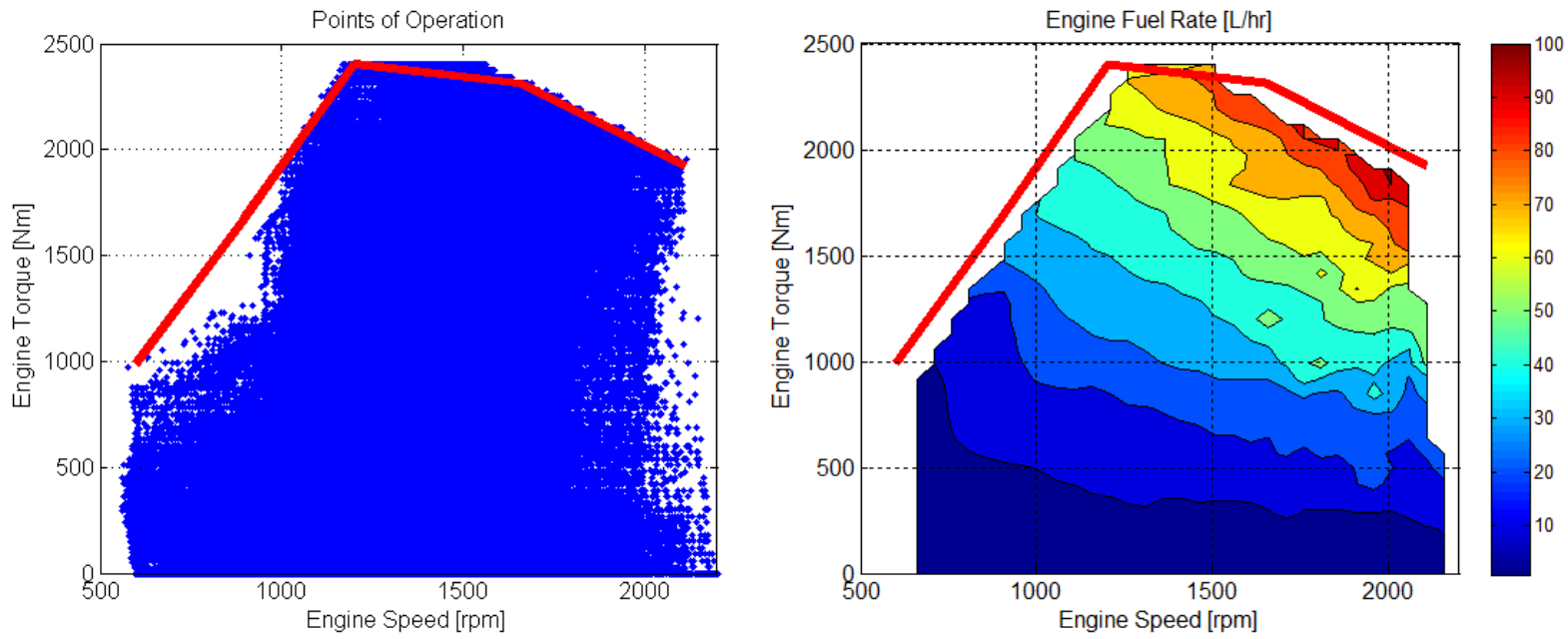

Figure 20. Engine map operation and fueling

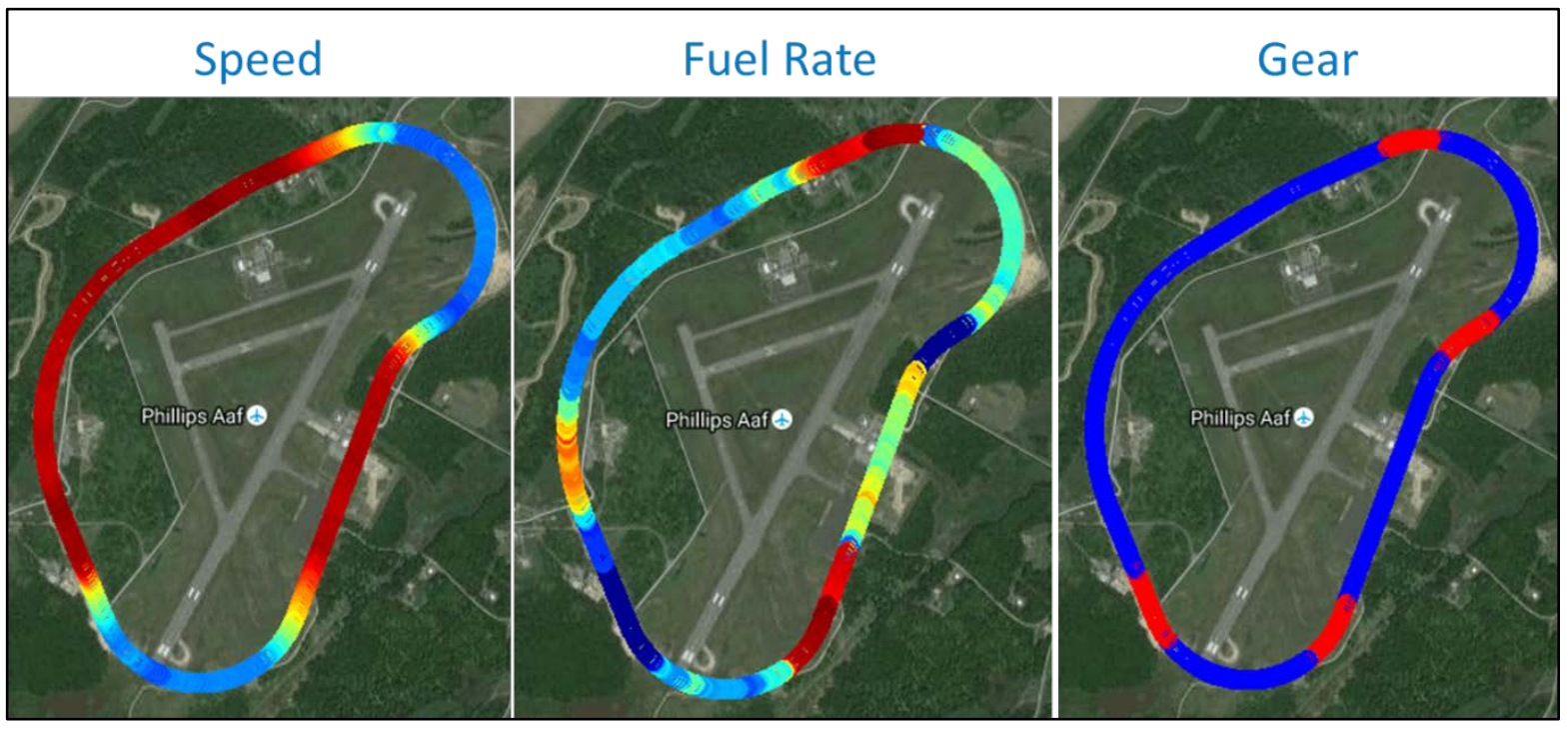

Figure 21. Data visualization over course map

Figure 22 shows engine speed versus vehicle speed, color-coded by engine fuel rate for the two vehicles. Note that truck T12 (M915A3) never enters the red color band as this vehicle has a lower horsepower rating than T13 (M915A5). The different gearing and wheel sizes between the two vehicles are also apparent. Truck T13 (M915A5) reaches $50 \mathrm{mph}$ in fourth gear at 2,200 rpm, whereas T12 (M915A3) is much closer to $2,000 \mathrm{rpm}$ when it reaches $50 \mathrm{mph}$. 

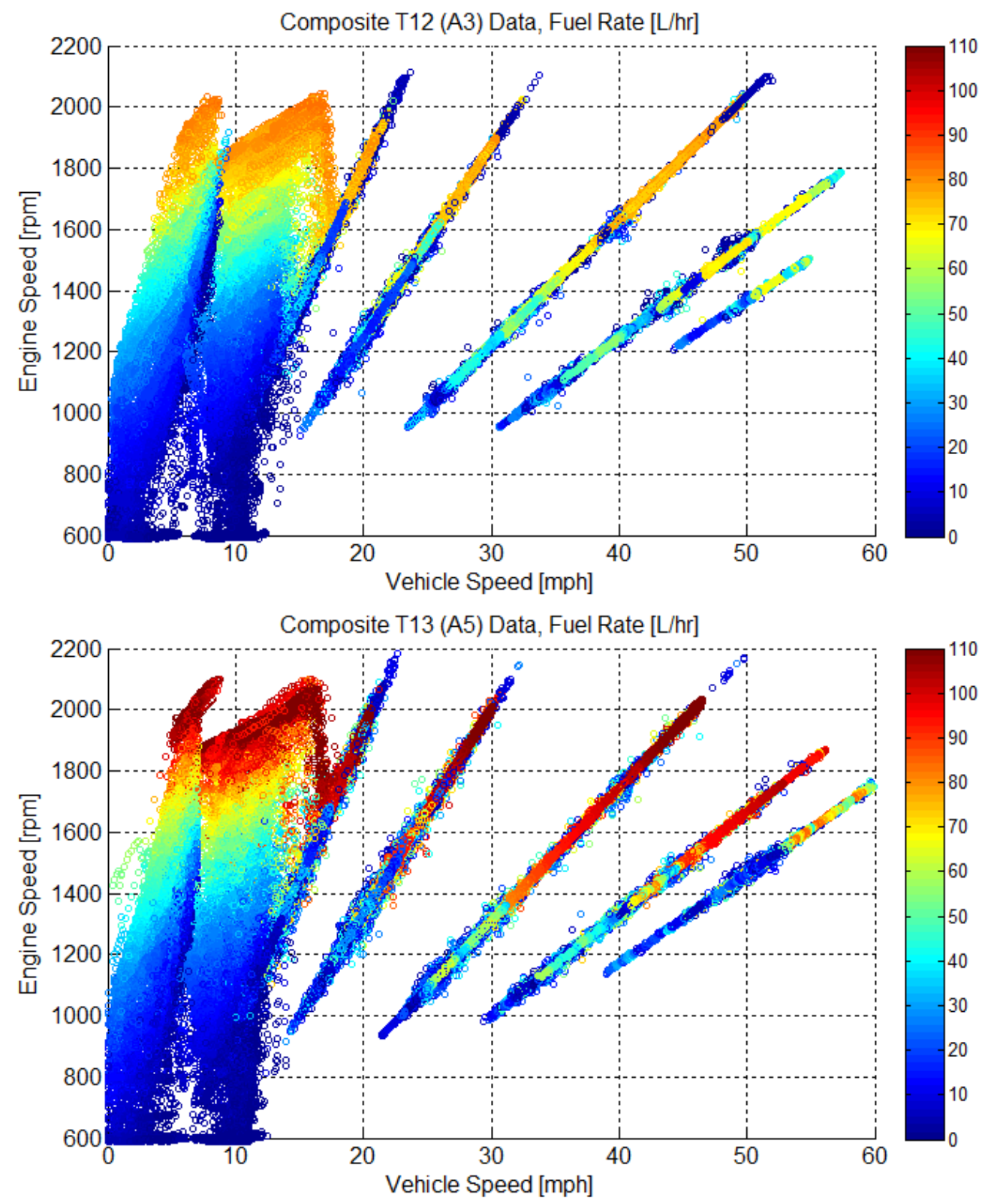

Figure 22. Engine speed versus vehicle speed 


\section{Conclusion}

The data acquisition system assembled for this testing gathered J1939-legislated CAN data, environmental data from an on-board weather station, position and velocity data from a GLONASS-enabled GPS, high-accuracy fuel flow data from an AVL KMA mobile fuel flow meter, as well as data from additional temperature and pressure sensors installed on the vehicle. All data were recorded by Vector GL2000 data loggers.

Testing results have benchmarked the performance of T12 and T13 over various courses at ATC. The AMAS Cruise control system did not show a benefit over a manual driver for any of the conditions tested. The Smart Cruise system demonstrated fuel savings exceeding the economy mode function, manual driving, and the project target on ATEF-Paved. However, there is still room for improvement from the Smart system on courses with additional obstacles, especially the large hills at CTA-C. The collected data provide deeper insight into the behavior of these vehicles under various test conditions and will allow the models (and on-vehicle efficiencyimproving implementation) to be refined before the next round of testing. 


\section{Appendix A. Required Signal List}

\begin{tabular}{|c|c|}
\hline \multicolumn{2}{|c|}{ Signal } \\
\hline \multirow{41}{*}{ 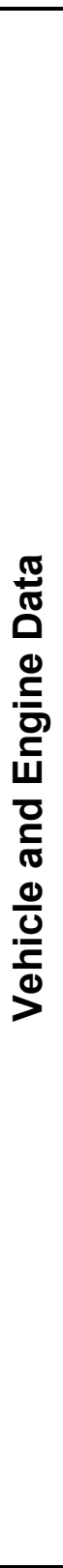 } & Accelerator Pedal Position \\
\hline & Engine Percent Load At Current Speed (\%) \\
\hline & Engine Speed \\
\hline & Engine Torque \\
\hline & Engine Total Average Fuel Economy \\
\hline & Engine Exhaust Gas Temperature (C) \\
\hline & Engine Coolant Temperature $(\mathrm{C})$ \\
\hline & Engine Turbocharger Boost Pressure (kPa) \\
\hline & Fan Drive State (bit) \\
\hline & Fan Speed (rpm) \\
\hline & Nominal Friction - Percent Torque (\%) \\
\hline & Total Vehicle Distance \\
\hline & Engine Speed At Point 2 (Engine Configuration) (rpm) \\
\hline & Engine Speed At Point 3 (Engine Configuration) (rpm) \\
\hline & Engine Speed At Point 4 (Engine Configuration) (rpm) \\
\hline & Engine Speed At Point 5 (Engine Configuration) (rpm) \\
\hline & $\begin{array}{l}\text { Engine Speed At High Idle Point } 6 \text { (Engine } \\
\text { Configuration)(rpm) }\end{array}$ \\
\hline & Calculated speed of the transmission output shaft. \\
\hline & $\begin{array}{l}\text { Engine Percent Torque At Point } 2 \text { (Engine } \\
\text { Configuration) (\%) }\end{array}$ \\
\hline & $\begin{array}{l}\text { Engine Percent Torque At Point } 3 \text { (Engine } \\
\text { Configuration) (\%) }\end{array}$ \\
\hline & $\begin{array}{l}\text { Engine Percent Torque At Point } 4 \text { (Engine } \\
\text { Configuration) }(\%)\end{array}$ \\
\hline & $\begin{array}{l}\text { Engine Percent Torque At Point } 5 \text { (Engine } \\
\text { Configuration) }(\%)\end{array}$ \\
\hline & Engine Reference Torque (Engine Configuration) (Nm) \\
\hline & Engine Intercooler Temperature (C) \\
\hline & Engine Fuel Temperature $1(\mathrm{C})$ \\
\hline & Engine Oil Temperature $1(\mathrm{C})$ \\
\hline & Engine Oil Pressure $(\mathrm{kPa})$ \\
\hline & Engine PTO Enable Switch (bit) \\
\hline & Wheel-Based Vehicle Speed (kph) \\
\hline & Cruise Control States \\
\hline & Cruise Control Active (bit) \\
\hline & Cruise Control Enable Switch (bit) \\
\hline & Cruise Control Accelerate Switch (bit) \\
\hline & Engine Fuel Rate $(1 / h)$ \\
\hline & Engine Instantaneous Fuel Economy (km/L) \\
\hline & Engine Average Fuel Economy $(\mathrm{km} / \mathrm{L})$ \\
\hline & Engine Air Inlet Temperature (C) \\
\hline & Engine Air Inlet Pressure (kPa) \\
\hline & Radiator In-Out \\
\hline & CAC In-Out \\
\hline & High Resolution Total Vehicle Distance $(\mathrm{m})$ \\
\hline
\end{tabular}

\begin{tabular}{|c|c|}
\hline & Signal \\
\hline \multirow{8}{*}{ 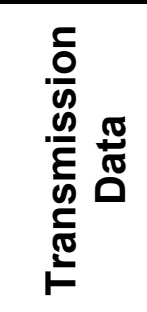 } & $\begin{array}{l}\text { Transmission Torque Converter Lockup Disable } \\
\text { Request }\end{array}$ \\
\hline & Transmission Input Shaft Speed (rpm) \\
\hline & Transmission Output Shaft Speed (rpm) \\
\hline & Transmission Torque Converter Lockup Engaged \\
\hline & Transmission Current Gear (gear value) \\
\hline & Transmission Selected Gear (gear value) \\
\hline & Transmission Actual Gear Ratio \\
\hline & Transmission Oil Temperature \\
\hline \multirow{5}{*}{ 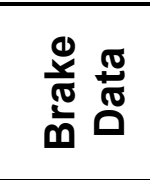 } & Brake Pedal Position \\
\hline & Brake Switch \\
\hline & Brake Application Pressure \\
\hline & Brake Primary Pressure \\
\hline & Brake Secondary Pressure \\
\hline \multirow{9}{*}{ 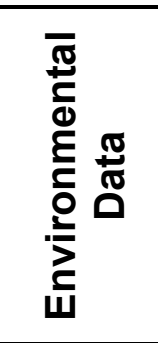 } & Compass Bearing \\
\hline & Altitude \\
\hline & Latitude \\
\hline & Longitude \\
\hline & Barometric Pressure (kPa) \\
\hline & Ambient Air Temperature (C) \\
\hline & Grade / Yaw \\
\hline & Wind speed / direction \\
\hline & $\begin{array}{l}\text { Time Stamp (from the GPS Antenna/Weather } \\
\text { Station) }\end{array}$ \\
\hline \multirow{2}{*}{ Battery } & Alternator Current \\
\hline & Battery Potential / Power Input 1 \\
\hline
\end{tabular}




\section{Appendix B. Actual Recorded Signal List with Units}

\begin{tabular}{|c|c|}
\hline MATLAB Name & Units \\
\hline AMB_AmbientAirTemp & [deg C] \\
\hline AMB EngAirlntakeTemp & {$[\operatorname{deg} C]$} \\
\hline AUXIO7__BPSL_FRONT_DRIVER & \\
\hline AUXIO7 BPSL FRONT PASSENGER & \\
\hline AUXIO7_BPSL_MID_DRIVER & \\
\hline AUXIO7_BPSL_MID_PASSENGER & \\
\hline AUXIO7_BPSL_REAR_PASSENGER & \\
\hline AVL_AK1_Density & {$[\mathrm{kg} / \mathrm{l}]$} \\
\hline AVL_AK1 Frequency & {$[\mathrm{Hz}]$} \\
\hline AVL_AK1_Fuel_Temp1 & [C] \\
\hline AVL_AK1_Fuel_Temp2 & \\
\hline AVL_AK2_Flow_Mass & {$[\mathrm{kg} / \mathrm{h}]$} \\
\hline $\mathrm{AVL}$ AK2 Flow_Vol & {$[/ / h]$} \\
\hline Airmar_Altitude & {$[\mathrm{m}]$} \\
\hline Airmar_Atmospheric_Pressure & {$[\mathrm{Pa}]$} \\
\hline Airmar_COG_True & [deg] \\
\hline Airmar Date & [days] \\
\hline Airmar Humidity & [\%] \\
\hline Airmar Latitude & [deg] \\
\hline Airmar_Longitude & [deg] \\
\hline Airmar_Mag_Variation & [deg] \\
\hline Num_Sats & \\
\hline Airmar_Rate_of_Turn & [deg/s] \\
\hline Airmar SOG & {$[\mathrm{m} / \mathrm{s}]$} \\
\hline Airmar Temperature & {$[\mathrm{K}]$} \\
\hline Airmar_Time & [sec] \\
\hline Airmar_Wind_Direction_Apparent & [deg] \\
\hline Airmar_Wind_Speed_Apparent & {$[\mathrm{m} / \mathrm{s}]$} \\
\hline CCVS CruiseCtrlAccelerateSwitch & \\
\hline CCVS CruiseCtrlActive & \\
\hline CCVS CruiseCtrlCoastSwitch & \\
\hline CCVS CruiseCtrlEnableSwitch & \\
\hline CCVS CruiseCtrIResumeSwitch & \\
\hline CCVS_CruiseCtrlSetSpeed & {$[\mathrm{km} / \mathrm{h}]$} \\
\hline CCVS_CruiseCtrlSetSwitch & \\
\hline CCVS CruiseCtrlStates & \\
\hline CCVS PTOGovernorState & \\
\hline CCVS ParkingBrakeSwitch & \\
\hline CCVS WheelBasedVehicleSpeed & {$[\mathrm{km} / \mathrm{h}]$} \\
\hline DD_FuelLevel1 & [\%] \\
\hline Digital_Dl_0 & \\
\hline EBC1_ABSFullyOperational & \\
\hline EBC1 ABSOffroadSwitch & \\
\hline EBC1 ABS_EBSAmberWarningSignal & \\
\hline EBC1 ASRBrakeCtrlActive & \\
\hline EBC1_ ASREngCtrlActive & \\
\hline EBC1 ASROffroadSwitch & \\
\hline EBC1 ATC_ASRInformationSignal & \\
\hline EBC1 AntiLockBrakingActive & \\
\hline EBC1_EBSBrakeSwitch & \\
\hline EBC1_ TrailerABSStatus & \\
\hline EBC1_TrctrMntdTrailerABSWarningSignal & \\
\hline EBC2 FrontAxleSpeed & {$[\mathrm{km} / \mathrm{h}]$} \\
\hline EBC2 RelativeSpeedFrontAxleLeftWheel & {$[\mathrm{km} / \mathrm{h}]$} \\
\hline EBC2 RelativeSpeedFrontAxleRightWheel & {$[\mathrm{km} / \mathrm{h}]$} \\
\hline EBC2 RelativeSpeedRearAxle1LeftWheel & {$[\mathrm{km} / \mathrm{h}]$} \\
\hline EBC2 RelativeSpeedRearAxle1RightWheel & {$[\mathrm{km} / \mathrm{h}]$} \\
\hline EBC2 RelativeSpeedRearAxle2LeftWheel & {$[\mathrm{km} / \mathrm{h}]$} \\
\hline EBC2 RelativeSpeedRearAxle2RightWheel & {$[\mathrm{km} / \mathrm{h}]$} \\
\hline EBC5 BrakeTempWarning & \\
\hline EBC5 FoundationBrakeUse & \\
\hline EBC5 HaltBrakeMode & \\
\hline
\end{tabular}

\begin{tabular}{|c|c|}
\hline MATLAB Name & Units \\
\hline EBC5_HillHolderMode & \\
\hline EBC5_XBRAccelerationLimit & {$\left[\mathrm{m} / \mathrm{s}^{2}\right]$} \\
\hline XBRActiveCtrlMode & \\
\hline EBC5_XBRSystemState & \\
\hline EC1 EngReferenceTorque & {$[\mathrm{Nm}]$} \\
\hline EEC1_ActlEngPrcntTorqueHighResolution & [\%] \\
\hline EEC1 ActualEngPercentTorque & {$[\%]$} \\
\hline EEC1 DriversDemandEngPercentTorque & [\%] \\
\hline EEC1 EngSpeed & [rpm] \\
\hline EEC1 EngStarterMode & \\
\hline EEC1 EngTorqueMode & \\
\hline EEC1_SrcAddrssOfCntrllngDvcForEngCtrl & \\
\hline EEC2 AccelPedalPos1 & [\%] \\
\hline EEC2 EngPercentLoadAtCurrentSpeed & {$[\%]$} \\
\hline EEC3 EnginesDesiredOperatingSpeed & [rpm] \\
\hline EEC3 EngnsDsrdOprtngSpdAsymmtryAdjstm & \\
\hline EEC3 NominalFrictionPercentTorque & [\%] \\
\hline EFL_P1_EngCoolantLevel & [\%] \\
\hline EFL_P1_EngOilPress & {$[\mathrm{kPa}]$} \\
\hline ERC1_ActualRetarderPercentTorque & [\%] \\
\hline ERC1_RetarderTorqueMode & \\
\hline ET1 EngCoolantTemp & [deg C] \\
\hline ET1_EngFuelTemp1 & [deg C] \\
\hline ET1 EngOilTemp1 & {$[\operatorname{deg} \mathrm{C}]$} \\
\hline ETC1_ProgressiveShiftDisable & \\
\hline ETC1__TransDrivelineEngaged & \\
\hline ETC1 TransInputShaftSpeed & [rpm] \\
\hline ETC1 TransOutputShaftSpeed & [rpm] \\
\hline ETC1_TransShiftlnProcess & \\
\hline ETC1_TrnsTorqueConverterLockupEngaged & \\
\hline ETC2 TransActualGearRatio & \\
\hline ETC2_TransCurrentGear & \\
\hline ETC2__TransCurrentRange & \\
\hline ETC2 TransRequestedRange & \\
\hline ETC2_TransSelectedGear & \\
\hline ETC7 TransEngCrankEnable & \\
\hline ETC7 TransMode1/ndicator & \\
\hline ETC7 TransMode2Indicator & \\
\hline ETC7 TransMode4Indicator & \\
\hline ETC7_TransRequestedGearFeedback & \\
\hline ETC7_TransShiftlnhibitIndicator & \\
\hline ETC7 TrnsRqstedRangeDisplayBlankState & \\
\hline ETC7 TrnsRqstedRangeDisplayFlashState & \\
\hline ETC8_ TransTorqueConverterRatio & \\
\hline FD_EstPercentFanSpeed & [\%] \\
\hline FD_FanDriveState & \\
\hline Garmin19x_COG_Mag & [deg] \\
\hline Garmin19x_COG_True & [deg] \\
\hline Garmin $19 x$ Elevation & {$[\mathrm{m}]$} \\
\hline Garmin19x_Error_H & [m] \\
\hline Garmin19x_Error_P & [m] \\
\hline Garmin19x_Error_V & [m] \\
\hline Garmin19x_Fix_Type & \\
\hline Garmin19x _Latitude & [deg] \\
\hline Garmin19x Longitude & [deg] \\
\hline Garmin19x_Num_Sats & \\
\hline Garmin19x SOG & {$[\mathrm{km} / \mathrm{h}]$} \\
\hline Garmin19x_UTC_Time & [sec] \\
\hline Garmin19x Velocity_East & {$[\mathrm{m} / \mathrm{s}]$} \\
\hline Garmin19x Velocity_North & {$[\mathrm{m} / \mathrm{s}]$} \\
\hline Garmin19x_Velocity_Up & {$[\mathrm{m} / \mathrm{s}]$} \\
\hline HOURS EngTotalHoursOfOperation & [hr] \\
\hline
\end{tabular}




\begin{tabular}{|l|l|}
\hline \multicolumn{1}{|c|}{ MATLAB Name } & Units \\
\hline HOURS_EngTotalRevolutions & {$[\mathrm{r}]$} \\
\hline HRW_FrontAxleLeftWheeISpeed & {$[\mathrm{km} / \mathrm{h}]$} \\
\hline HRW_FrontAxleRightWheelSpeed & {$[\mathrm{km} / \mathrm{h}]$} \\
\hline HRW_RearAxleLeftWheelSpeed & {$[\mathrm{km} / \mathrm{h}]$} \\
\hline HRW_RearAxleRightWheeISpeed & {$[\mathrm{km} / \mathrm{h}]$} \\
\hline IC1_EngIntakeManifold1Press & {$[\mathrm{kPa}]$} \\
\hline LC_CenterStopLightCmd & \\
\hline LC_LightingDataRqCmd & \\
\hline LD_BackUpLightAndAlarmHorn & \\
\hline LD_CenterStopLight & \\
\hline LD_HighBeamHeadLightData & \\
\hline LD_LeftStopLight & \\
\hline LD_LeftTurnSignalLights & \\
\hline LD_LowBeamHeadLightData & \\
\hline LD_RightStopLight & \\
\hline LD_RightTurnSignalLights & \\
\hline LD_TractorMarkerLight & {$[\mathrm{km} / \mathrm{L}]$} \\
\hline LFE_EngAverageFuelEconomy & {$[\mathrm{L}]$} \\
\hline LFE_EngFueIRate & {$[\mathrm{km} / \mathrm{L}]$} \\
\hline LFE_EnglnstantaneousFuelEconomy & \\
\hline ML_BlackOutBrake_StopLampSelect & \\
\hline ML_ConvoyDrivingLampSelect & \\
\hline ML_FrontBlackOutMarkerLampSelect & \\
\hline ML_OprtrsBlackOutIntensitySelection & \\
\hline OWW_FrontNonoperatorWasherSwitch & {$[\%]$} \\
\hline OWW_FrontNonoperatorWiperSwitch & \\
\hline OWW_FrontOperatorWasherSwitch & \\
\hline OWW_FrontOperatorWiperSwitch & \\
\hline OWW_RearWasherFunction & \\
\hline OWW_RearWiperSwitch & \\
\hline PIS_BrakeControIPressure & \\
\hline PIS_BrakePedalPos & \\
\hline PIS_EngOverrideCtrIMode & \\
\hline PIS_EngRequestedTorque_TorqueLimit & \\
\hline PTO_PowerTakeoffSetSpeed & \\
\hline SHUTDN_EngProtectionSystemConfig & \\
\hline TC1__RequestedPercentClutchSlip & \\
\hline TC1_TransRequestedGear & \\
\hline TC1_TransRequestedLaunchGear & \\
\hline
\end{tabular}

\begin{tabular}{|c|c|}
\hline MATLAB Name & Units \\
\hline TC1 TrnsShftSlectorDisplayModeSwitch & \\
\hline TRF1_TransOilLevelCountdownTimer & \\
\hline TransOilLevelHigh Low & [L] \\
\hline TransOilLevelMeasurementStatus & \\
\hline TransOilTemp & {$[\operatorname{deg} \mathrm{C}]$} \\
\hline EngOverrideCtrlMode & \\
\hline EngRequestedSpeed SpeedLimit & [rpm] \\
\hline EngRequestedTorqueHighResolution & [\%] \\
\hline EngRequestedTorque TorqueLimit & {$[\%]$} \\
\hline MessageChecksum & \\
\hline MessageCounter & \\
\hline TSC1CtrlPurpose & \\
\hline TSC1TransRate & \\
\hline CAC In & [C] \\
\hline CAC Out & [C] \\
\hline Temp & [C] \\
\hline Rad In & [C] \\
\hline Rad Out & [C] \\
\hline Time & [s] \\
\hline ROPBrakeCtrlActive & \\
\hline ROPEngCtrlActive & \\
\hline VDCBrakeLightRq & \\
\hline VDCFullyOperational & \\
\hline VDCInformationSignal & \\
\hline YCBrakeCtrlActive & \\
\hline YCEngCtrlActive & \\
\hline LateralAcceleration & {$\left[\mathrm{m} / \mathrm{s}^{2}\right]$} \\
\hline LongitudinalAcceleration & {$\left[\mathrm{m} / \mathrm{s}^{2}\right]$} \\
\hline SteerWheelAngle & [rad] \\
\hline SteerWheelTurnCounter & [turns] \\
\hline YawRate & [rad/s] \\
\hline HghRsolutionTotalVehicleDistance & {$[\mathrm{km}]$} \\
\hline HighResolutionTripDistance & {$[\mathrm{km}]$} \\
\hline VEP1 BatteryPotential_PowerInput1 & [V] \\
\hline Voltage $\quad$ AVL & [V] \\
\hline Voltage AirPressure & [V] \\
\hline Voltage Shunt $\mathrm{mV}$ & {$[\mathrm{mV}]$} \\
\hline
\end{tabular}




\section{Appendix C. Bill of Materials}

\begin{tabular}{|c|c|c|c|c|}
\hline Item \# & Description & Supplier & Supplier Part \# & Qty \\
\hline 1 & Fuel Flow Meter Assembly & & & \\
\hline 2 & \begin{tabular}{|l|l} 
& AVL - KMA Mobile Measurement System (Fuel Flow Meter)
\end{tabular} & \multirow{6}{*}{$\begin{array}{l}\text { AVL Test } \\
\text { Systems }\end{array}$} & & 1 \\
\hline 3 & \begin{tabular}{l|l} 
& AVL KMA Mobil Type 150 (Measurement Mod.) \\
\end{tabular} & & TNMES150.01 & 1 \\
\hline 4 & AVL KMA Mobile Density Meter & & TNMOBDENS.01 & 1 \\
\hline 5 & AVL KMA Mobile Cond. Truck (Mod. Diesel) & & TNCOND3024.01 & 1 \\
\hline 6 & AVL KMA Mobile Addit. Connection Kit & & TNCONEKIT.01 & 1 \\
\hline 7 & Packing and Duty & & VSVFRE-119NA3 & 1 \\
\hline 8 & Weather Station Assembly & & & \\
\hline 9 & Airmar 220WX WeatherStation Instrument & \multirow{2}{*}{ iMarine USA } & WS-220WX-RH & 1 \\
\hline 10 & Airmar NMEA2000 Communication Cable $6.5 \mathrm{ft}$ & & WS2-CO2 & 1 \\
\hline 11 & \begin{tabular}{|l|l} 
& Mounting Bracket Fabricated by Primus \\
\end{tabular} & & & \\
\hline 12 & DAQ Unit Assembly & & & \\
\hline 13 & Vector GL2000 Data Logger (Standard 4x CAN HS) & Vector & $28090 S$ & 1 \\
\hline 14 & \begin{tabular}{|l|l|} 
GL2000 Transfer Request License \\
\end{tabular} & Vector & 28117 & 1 \\
\hline 15 & GL2000 GPS Receiver G-STAR IV & Vector & 28100 & 1 \\
\hline 16 & VN1610 CAN Network Interface & Vector & 7150 & 1 \\
\hline 17 & CANcable 2 Y & Vector & 5075 & 1 \\
\hline 18 & Sierra Wireless - AirLink LS300 EV-DO Verizon Modem & Newegg.com & LS300 EV-DO & 1 \\
\hline 19 & CANopen slave module, 8 channel 16 -bit voltage input & ICP DAS USA & $2017 \mathrm{C}$ & 1 \\
\hline 20 & CANopen slave module, 8-channel thermocouple input & ICP DAS USA & $2018 C$ & 1 \\
\hline 21 & CANopen slave module, 8-ch counter / digital input & ICP DAS USA & $2088 C$ & 1 \\
\hline 22 & Omega signal conditioner for frequency/pulse input & Omega & iDRN-FP & 1 \\
\hline 23 & RS-232 to CAN protocol converter & & & 2 \\
\hline 24 & \begin{tabular}{|l|l|} 
& Black plastic electronics enclosure \\
\end{tabular} & McMaster-Carr & $7593 K 28$ & 2 \\
\hline 25 & Voltage Regulator - $5 \mathrm{~V}$ & SparkFun & L7805 & 2 \\
\hline 26 & Arduino Pro Mini $328-5 \mathrm{~V} / 16 \mathrm{MHz}$ & SparkFun & DEV-11113 & 2 \\
\hline 27 & MAX3232 Transceiver & SparkFun & BOB-11189 & 2 \\
\hline 28 & Proto Half-sized Breadboard PCB 3-pack & Adafruit & 571 & 1 \\
\hline 29 & MCP2515 Serial to CAN Development Board & Amazon & B015W4D9WY & 2 \\
\hline 30 & PVC Junction Box enclosure 12in x 12in x 6in & Home Depot & & 1 \\
\hline 31 & DIN 3 Rail (1 meter long) & McMaster-Carr & $8961 K 15$ & 1 \\
\hline 32 & DIN-Rail mount terminal blocks, standard two circuit & McMaster-Carr & $7641 K 71$ & 10 \\
\hline 33 & DIN-Rail mount terminal blocks, end covers & McMaster-Carr & $7641 K 72$ & 3 \\
\hline 34 & DIN-Rail mount terminal blocks, ground block & McMaster-Carr & $7641 \mathrm{~K} 81$ & 1 \\
\hline 35 & DIN-Rail mount terminal blocks, fuse block & McMaster-Carr & $7641 K 36$ & 1 \\
\hline 36 & DIN-Rail mount terminal blocks, end stops & McMaster-Carr & $7641 K 73$ & 2 \\
\hline 37 & DIN-Rail mount terminal blocks, jumpers & McMaster-Carr & $7641 K 74$ & 4 \\
\hline 38 & Stranded Copper Wire, 18 gauge, 50ft, Black & McMaster-Carr & $8054 T 15$ & 1 \\
\hline 39 & Stranded Copper Wire, 18 gauge, 50ft, Red & McMaster-Carr & $8054 T 15$ & 1 \\
\hline 40 & Stranded Copper Wire, 18 gauge, 50ft, Green & McMaster-Carr & $8054 T 15$ & 1 \\
\hline 41 & Stranded Copper Wire, 18 gauge, 50ft, Yellow & McMaster-Carr & $8054 T 15$ & 1 \\
\hline 42 & Communication Cable, 4 wire, $100 \mathrm{ft}$ & McMaster-Carr & $8280 T 32$ & 1 \\
\hline 43 & Communication Cable, 2 wire, $100 \mathrm{ft}$ & McMaster-Carr & $8280 T 31$ & 1 \\
\hline 44 & DB9 connection kit, plug & McMaster-Carr & $2146 \mathrm{~T} 11$ & 4 \\
\hline 45 & \begin{tabular}{|l|l} 
& DB9 connection kit, socket \\
\end{tabular} & McMaster-Carr & $2146 \mathrm{~T} 12$ & 4 \\
\hline 46 & Sensors, cables etc. & & & \\
\hline 47 & Garmin 19x HVS GLONASS enabled GPS (NMEA 0183) & Garmin & 010-01010-00 & 1 \\
\hline 48 & Alternator Current Shunt, 50mV @ 150 A & Ram Meter Inc. & 20M150A50 & 1 \\
\hline 49 & Alternator Current Shunt, 50mV @ 500 A & Ram Meter Inc. & 21M500A50 & 1 \\
\hline 50 & Pipe Fitting, 1/4 NPT Female x Butt-Weld Female & McMaster-Carr & $4464 \mathrm{~K} 471$ & 5 \\
\hline 51 & Straight Adapter for $1 / 8$ " Tube OD, x 1/4 NPT Male & McMaster-Carr & 5272K291 & 5 \\
\hline 52 & Type K Thermocouple, 0.125 × 6", ungrounded & Omega & KMQSS-125U-6 & 5 \\
\hline 53 & Thermocouple Extension Wire, Type K, 500ft & Omega & EXPP-K-20-500 & 1 \\
\hline 54 & Pressure Transducer, 150 psi & Omega & PX309-150G5V & 1 \\
\hline
\end{tabular}




\title{
Appendix D. Configuration Settings
}

The configuration settings for the instrumentation and various modules used in the data acquisition system are shown below.

\section{Garmin 19x GPS Configuration}

\section{RS-232 Serial Commands}

\author{
\$PGRMO,,2*75 \\ \$PGRMC,A,,,,,,,A, $8,1,1,1$ \\ \$PGRMC1,,1,2,,,1,W,N \\ \$PGRMC2,5,LOW,GLONASS,ON,GP,PR0,0 \\ \$PGRMO,GPGGA, 1,1 \\ \$PGRMO,GPVTG, 1,1 \\ \$PGRMO,PGRMV,1,1 \\ \$PGRMO,PGRME, 1,1
}

\section{Database Messages and Signals}

\begin{tabular}{|c|c|c|c|}
\hline Name & ID & ID-Format & DLC [Byte] \\
\hline$x^{+} \bowtie$ GPGGA_Lat_Lon & $0 \times 7 A 2$ & CAN Standard & 8 \\
\hline$x^{+} \otimes$ GPGGA_UTC_Time & $0 \times 7 \mathrm{~A} 1$ & CAN Standard & 8 \\
\hline$x^{+} \otimes$ GPVTG_COG_SOG & $0 \times 7 \mathrm{A3}$ & CAN Standard & 8 \\
\hline$x^{+} \otimes$ PGRME_Error & $0 \times 7 A 5$ & CAN Standard & 8 \\
\hline$x^{+} \otimes$ PGRMV_Vel_Dir & $0 \times 7 A 4$ & CAN Standard & 8 \\
\hline
\end{tabular}

\begin{tabular}{|c|c|c|c|c|c|c|c|c|}
\hline Name & Length [Bit] & Byte Order & Value Type & Factor & Offset & Minimum & Maximum & Unit \\
\hline$\sim$ COG_Mag & 16 & Intel & Unsigned & 0.1 & 0 & 0 & 6553.5 & deg \\
\hline$\sim$ COG_True & 16 & Intel & Unsigned & 0.1 & 0 & 0 & 6553.5 & deg \\
\hline$\sim$ Elevation & 20 & Intel & Signed & 0.1 & 0 & -52428.8 & 52428.7 & $\mathrm{~m}$ \\
\hline$\sim$ Error_H & 16 & Intel & Unsigned & 0.01 & 0 & 0 & 655.35 & $\mathrm{~m}$ \\
\hline$\sim$ Error_P & 16 & Intel & Unsigned & 0.01 & 0 & 0 & 655.35 & $\mathrm{~m}$ \\
\hline$\sim$ Error_V & 16 & Intel & Unsigned & 0.01 & 0 & 0 & 655.35 & $\mathrm{~m}$ \\
\hline$\sim$ Fix_Type & 4 & Intel & Unsigned & 1 & 0 & 0 & 15 & \\
\hline$\sim$ Latitude & 32 & Intel & Signed & $1 \mathrm{e}-006$ & 0 & -2147.48 & 2147.48 & deg \\
\hline$\sim$ Longitude & 32 & Intel & Signed & $1 \mathrm{e}-006$ & 0 & -2147.48 & 2147.48 & deg \\
\hline$\sim$ Num_Sats & 8 & Intel & Unsigned & 1 & 0 & 0 & 255 & \\
\hline$\sim S O G$ & 24 & Intel & Unsigned & 0.01 & 0 & 0 & 167772 & $\mathrm{kmph}$ \\
\hline ح UTC_Time & 32 & Intel & Unsigned & 0.1 & 0 & 0 & $4.29497 e+008$ & $\sec$ \\
\hline$\sim$ Velocity_East & 16 & Intel & Signed & 0.01 & 0 & -327.68 & 327.67 & mps \\
\hline$\sim$ Velocity_North & 16 & Intel & Signed & 0.01 & 0 & -327.68 & 327.67 & $\mathrm{mps}$ \\
\hline$\sim$ Velocity_Up & 16 & Intel & Signed & 0.01 & 0 & -327.68 & 327.67 & mps \\
\hline
\end{tabular}




\section{Airmar 220WX Weather Station}

The default CAN configuration was used for the weather station, which included the following output messages.

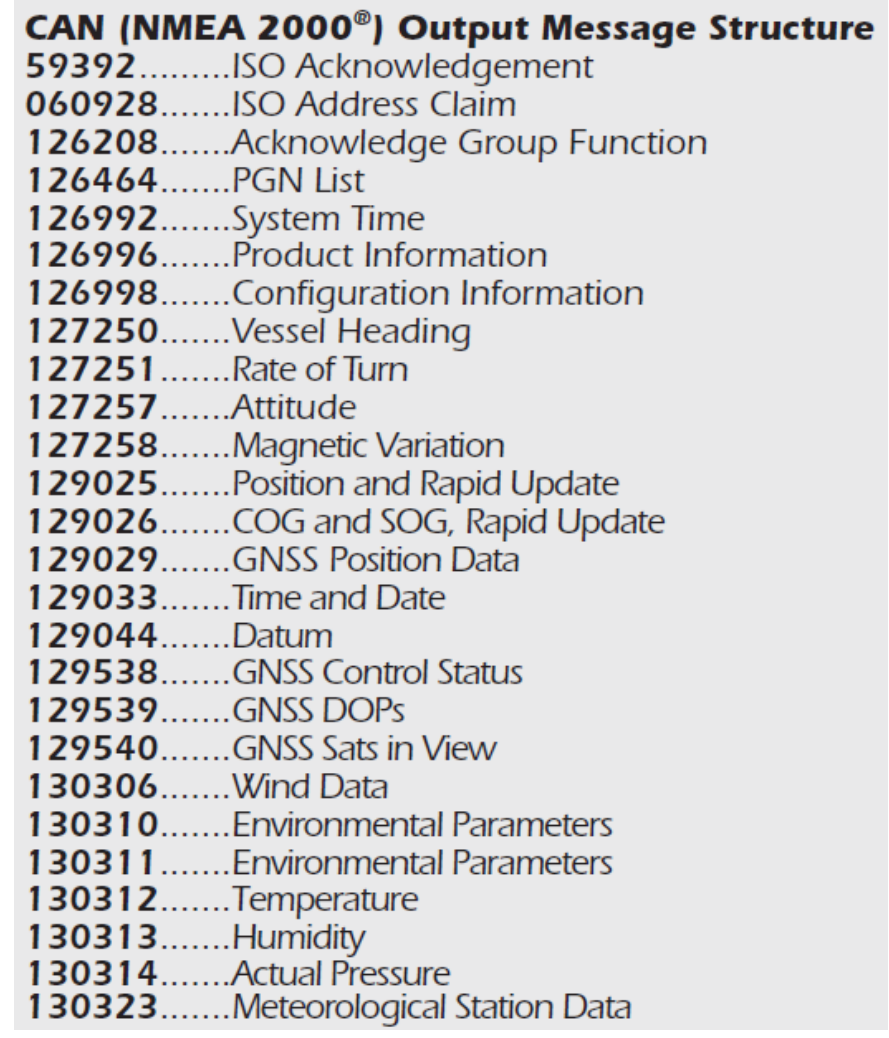

\section{ICP DAS I/O Modules}

The data acquisition system included three types of CANopen I/O modules to translate signals to the CAN. The addresses of the modules were configured with the external DIP switches as follows:

1. Voltage

2. Temperature

3. Counter

Then all three modules were programmed using the following CANopen commands:

\begin{tabular}{|c|c|c|c|c|c|c|c|c|c|}
\hline 601 & $\mathrm{Tx}$ & & $2 B$ & 15 & 10 & 00 & 64 & 00 & 00 \\
\hline 601 & $\mathrm{Tx}$ & d 8 & $2 B$ & 01 & 18 & 05 & C 8 & 00 & 00 \\
\hline 601 & $\mathrm{Tx}$ & d 8 & $2 B$ & 02 & 18 & 05 & C8 & 00 & 00 \\
\hline 601 & $\mathrm{Tx}$ & d 8 & $2 F$ & 04 & 20 & 01 & OC & 00 & 00 \\
\hline 601 & $\mathrm{Tx}$ & d 8 & $2 \mathrm{~F}$ & 04 & 20 & 02 & OC & 00 & 00 \\
\hline 601 & $\mathrm{Tx}$ & d 8 & $2 F$ & 04 & 20 & 03 & 09 & 00 & 00 \\
\hline 601 & $\mathrm{Tx}$ & d 8 & $2 \mathrm{~F}$ & 04 & 20 & 04 & 09 & 00 & 00 \\
\hline 601 & $\mathrm{Tx}$ & d 8 & 23 & 10 & 10 & 01 & 73 & 61 & 76 \\
\hline
\end{tabular}




$\begin{array}{llllllllllll}602 & \mathrm{Tx} & \mathrm{d} & 8 & 2 \mathrm{~B} & 15 & 10 & 00 & 64 & 00 & 00 & 00 \\ 602 & \mathrm{Tx} & \mathrm{d} & 8 & 2 \mathrm{~B} & 01 & 18 & 05 & \mathrm{E} 8 & 03 & 00 & 00 \\ 602 & \mathrm{Tx} & \mathrm{d} & 8 & 2 \mathrm{~B} & 02 & 18 & 05 & \mathrm{E} 8 & 03 & 00 & 00 \\ 602 & \mathrm{Tx} & \mathrm{d} & 8 & 2 \mathrm{~F} & 04 & 20 & 01 & 0 \mathrm{~F} & 00 & 00 & 00 \\ 602 & \mathrm{Tx} & \mathrm{d} & 8 & 2 \mathrm{~F} & 04 & 20 & 02 & 0 \mathrm{~F} & 00 & 00 & 00 \\ 602 & \mathrm{Tx} & \mathrm{d} & 8 & 2 \mathrm{~F} & 04 & 20 & 03 & 0 \mathrm{~F} & 00 & 00 & 00 \\ 602 & \mathrm{Tx} & \mathrm{d} & 8 & 2 \mathrm{~F} & 04 & 20 & 04 & 0 \mathrm{~F} & 00 & 00 & 00 \\ 602 & \mathrm{Tx} & \mathrm{d} & 8 & 2 \mathrm{~F} & 04 & 20 & 05 & 0 \mathrm{~F} & 00 & 00 & 00 \\ 602 & \mathrm{Tx} & \mathrm{d} & 8 & 2 \mathrm{~F} & 04 & 20 & 06 & 0 \mathrm{~F} & 00 & 00 & 00 \\ 602 & \mathrm{Tx} & \mathrm{d} & 8 & 2 \mathrm{~F} & 04 & 20 & 07 & 0 \mathrm{~F} & 00 & 00 & 00 \\ 602 & \mathrm{Tx} & \mathrm{d} & 8 & 2 \mathrm{~F} & 04 & 20 & 08 & 0 \mathrm{~F} & 00 & 00 & 0 \\ 602 & \mathrm{Tx} & \mathrm{d} & 8 & 2 \mathrm{~F} & 21 & 20 & 01 & 01 & 00 & 00 & 00 \\ 602 & \mathrm{Tx} & \mathrm{d} & 8 & 23 & 10 & 10 & 01 & 73 & 61 & 76 & 65 \\ 603 & & & & & & & & & & & \\ 6 x & \mathrm{~d} & 8 & 2 \mathrm{~B} & 00 & 18 & 05 & 64 & 00 & 00 & 00 \\ 603 & \mathrm{Tx} & \mathrm{d} & 8 & 2 \mathrm{~B} & 01 & 18 & 05 & \mathrm{C} 8 & 00 & 00 & 00 \\ 603 & \mathrm{Tx} & \mathrm{d} & 8 & 2 \mathrm{~B} & 02 & 18 & 05 & \mathrm{C} 8 & 00 & 00 & 00 \\ 603 & \mathrm{Tx} & \mathrm{d} & 8 & 23 & 10 & 10 & 01 & 73 & 61 & 76 & 65\end{array}$

\begin{tabular}{cllllllll}
\hline Name & Length [Bit] & Byte Order & Value Type & Factor & Offset & Minimum & Maximum & Unit \\
\hline AI_ch0 & 16 & Intel & Signed & 0.00457764 & 0 & -150 & 149.995 & $\mathrm{mV}$ \\
$\sim$ AI_ch1 & 16 & Intel & Signed & 0.00457764 & 0 & -150 & 149.995 & $\mathrm{mV}$ \\
$\sim$ AI_ch2 & 16 & Intel & Signed & 0.000152588 & 0 & -5 & 4.99985 & $\mathrm{~V}$ \\
$\sim$ AI_ch3 & 16 & Intel & Signed & 0.000152588 & 0 & -5 & 4.99985 & $\mathrm{~V}$ \\
$\sim$ AI_ch4 & 16 & Intel & Signed & 0.000305176 & 0 & -10 & 9.99969 & $\mathrm{~V}$ \\
$\sim$ AI_ch5 & 16 & Intel & Signed & 0.000305176 & 0 & -10 & 9.99969 & $\mathrm{~V}$ \\
$\sim$ AI_ch6 & 16 & Intel & Signed & 0.000305176 & 0 & -10 & 9.99969 & $\mathrm{~V}$ \\
$\sim$ AI_ch7 & 16 & Intel & Signed & 0.000305176 & 0 & -10 & 9.99969 & $\mathrm{~V}$ \\
$\sim$ Counter_0 & 32 & Intel & Unsigned & 1 & 0 & 0 & $4.29497 \mathrm{e}+009$ & \\
$\sim$ Counter_1 & 32 & Intel & Unsigned & 1 & 0 & 0 & $4.29497 \mathrm{e}+009$ & \\
$\sim$ Counter_2 & 32 & Intel & Unsigned & 1 & 0 & 0 & $4.29497 \mathrm{e}+009$ & \\
$\sim$ Counter_3 & 32 & Intel & Unsigned & 1 & 0 & 0 & $4.29497 \mathrm{e}+009$ & \\
$\sim$ DI_0 & 1 & Intel & Unsigned & 1 & 0 & 0 & 1 & \\
$\sim$ DI_1 & 1 & Intel & Unsigned & 1 & 0 & 0 & 1 & \\
$\sim$ DI_2 & 1 & Intel & Unsigned & 1 & 0 & 0 & 1 & \\
$\sim$ DI_3 & 1 & Intel & Unsigned & 1 & 0 & 0 & 1 & \\
$\sim$ DI_4 & 1 & Intel & Unsigned & 1 & 0 & 0 & 1 & \\
$\sim$ DI_5 & 1 & Intel & Unsigned & 1 & 0 & 0 & 1 & \\
$\sim$ DI_6 & 1 & Intel & Unsigned & 1 & 0 & 0 & 1 & \\
$\sim$ DI_7 & 1 & Intel & Unsigned & 1 & 0 & 0 & 1 & \\
$\sim$ TC_ch0 & 16 & Intel & Signed & 0.0418714 & 0 & -1372.04 & 1372 & ${ }^{\circ} \mathrm{C}$ \\
$\sim$ TC_ch1 & 16 & Intel & Signed & 0.0418714 & 0 & -1372.04 & 1372 & ${ }^{\circ} \mathrm{C}$ \\
$\sim$ TC_ch2 & 16 & Intel & Signed & 0.0418714 & 0 & -1372.04 & 1372 & ${ }^{\circ} \mathrm{C}$ \\
$\sim$ TC_ch3 & 16 & Intel & Signed & 0.0418714 & 0 & -1372.04 & 1372 & ${ }^{\circ} \mathrm{C}$ \\
$\sim$ TC_ch4 & 16 & Intel & Signed & 0.0418714 & 0 & -1372.04 & 1372 & ${ }^{\circ} \mathrm{C}$ \\
$\sim$ TC_ch5 & 16 & Intel & Signed & 0.0418714 & 0 & -1372.04 & 1372 & ${ }^{\circ} \mathrm{C}$ \\
$\sim$ TC_ch6 & 16 & Intel & Signed & 0.0418714 & 0 & -1372.04 & 1372 & ${ }^{\circ} \mathrm{C}$ \\
$\sim$ TC_ch7 & 16 & Intel & Signed & 0.0418714 & 0 & -1372.04 & 1372 & ${ }^{\circ} \mathrm{C}$
\end{tabular}




\section{Vector GL2000 Configuration}

\section{CAN channels \\ D CAN 1 \\ $\square$ CAN 2}

$\begin{array}{ll}250,000 \mathrm{Bd} & = \\ 250,000 \mathrm{Bd} & \end{array}$

$\square$ Output/ACK

v Output/ACK

( Keeps logger awake

$\checkmark$ Keeps logger awake $\square$ Log enror frames

Databases

$$
\text { Add... }
$$

\section{Remove}

\section{Replace..}

\begin{tabular}{|c|c|}
\hline File Name & Network \\
\hline Oesc Airmar_Display.dbc & \\
\hline Uarg Garmin_19x_GPS.dbc & \\
\hline पिe ICP_DAS.dbc & \\
\hline U1060 J1939_Display.dbc & \\
\hline Dese AVL_AK.dbc & \\
\hline प⿺辶冋:2016-09-14_GL2000_Config & \\
\hline
\end{tabular}

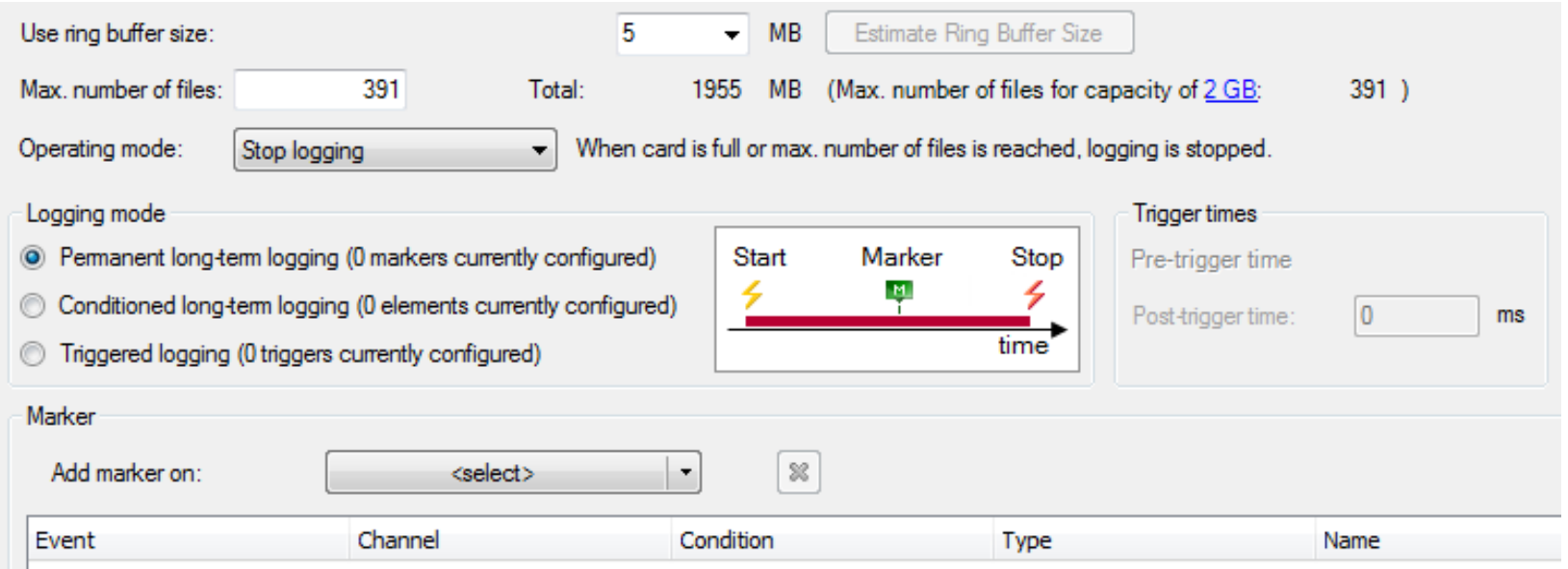




\begin{tabular}{|c|c|c|c|c|c|c|}
\hline \multicolumn{7}{|l|}{ Filters } \\
\hline \multirow{2}{*}{$\begin{array}{l}\text { Add filter: } \\
\text { Active }\end{array}$} & \multicolumn{2}{|c|}{\begin{tabular}{l|l|} 
sselect $>$ & - \\
\end{tabular}} & \multirow[b]{2}{*}{ Type } & \multirow[b]{2}{*}{ Channel } & \multirow[b]{2}{*}{ Condition } & \multirow[b]{2}{*}{ 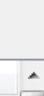 } \\
\hline & Action & Rate & & & & \\
\hline$\nabla$ & $\oplus$ Pass & all frames & Default & All & & \\
\hline$\nabla$ & e Stop & & 10 Symbolic CAN message & CAN2 & Datum (ID: 435688483x, DB: Airmar_Display) & \\
\hline$\nabla$ & e stop & & 0 Symbolic CAN message & CAN2 & GNSS_DOPS (ID: 435815203x, DB: Airmar_Display) & \\
\hline 目 & e Stop & & 7 Symbolic CAN message & CAN2 & GNSS_Sats_in_View (ID: 435815459x, DB: Airmar_Display) & \\
\hline 目 & O Stop & & 7 Symbolic CAN message & CAN2 & Meteorological_Station_Data (ID: 436015907x, DB: Airmar_Display) & \\
\hline 目 & O Stop & & 대 CAN channel & CAN1 & & \\
\hline$\nabla$ & (9) Pass & all frames & Symbolic CAN message & CAN1 & ACC1 (ID: 285110058x, DB: J1939_Display) & \\
\hline$\nabla$ & (9 Pass & all frames & 7 Symbolic CAN message & CAN1 & AMB (ID: 419362048x, DB: J1939_Display) & \\
\hline$\nabla$ & Q Limit & 1 frame per $1000 \mathrm{~ms}$ & 4 Symbolic CAN message & CAN1 & AUXIO1 (ID: 218028327x, DB: J1939_Display) & \\
\hline$\nabla$ & Q Limit & 1 frame per $1000 \mathrm{~ms}$ & 10 Symbolic CAN message & CAN1 & AUXIO2 (ID: $413607735 x$, DB: J1939_Display) & \\
\hline 目 & Q Limit & 1 frame per $1000 \mathrm{~ms}$ & Symbolic CAN message & CAN1 & AUXIO3 (ID: 413542374x, DB: J1939_Display) & \\
\hline$\nabla$ & $Q_{\gamma}$ Limit & 1 frame per $100 \mathrm{~ms}$ & 7 Symbolic CAN message & CAN1 & AUXIO7 (ID: 412942054x, DB: J1939_Display) & $\equiv$ \\
\hline 目 & (1) Pass & all frames & 7 Symbolic CAN message & CAN1 & CCVS (ID: 419361024x, DB: J1939_Display) & \\
\hline 目 & (9) Pass & all frames & 7 Symbolic CAN message & CAN1 & DD (ID: 419364070x, DB: J1939_Display) & \\
\hline$\nabla$ & (1) Pass & all frames & 7 Symbolic CAN message & CAN1 & EBC1 (ID: 418382091x, DB: J1939_Display) & \\
\hline$\nabla$ & (1) Pass & all frames & 7 Symbolic CAN message & CAN1 & EBC2 (ID: 419348235x, DB: J1939_Display) & \\
\hline$\nabla$ & (1) Pass & all frames & 0 Symbolic CAN message & CAN1 & EBC5 (ID: 419283979x, DB: J1939_Display) & \\
\hline 目 & (1) Pass & all frames & 7 Symbolic CAN message & CAN1 & EC1 (ID: 486466304x, DB: J1939_Display) & \\
\hline$\nabla$ & $\theta_{\gamma}$ Limit & 1 frame per $50 \mathrm{~ms}$ & 8 Symbolic CAN message & CAN1 & EEC1 (ID: 217056256x, DB: J1939_Display) & \\
\hline 目 & $Q_{-}$Limit & 1 frame per $50 \mathrm{~ms}$ & 7 Symbolic CAN message & CAN1 & EEC2 (ID: 217056000x, DB: J1939_Display) & \\
\hline D & $\odot$ Pass & all frames & 7 Symbolic CAN message & CAN1 & EEC3 (ID: 419356416x, DB: J1939_Display) & \\
\hline$\nabla$ & $\odot$ Pass & all frames & 0 Symbolic CAN message & CAN1 & EFL_P1 (ID: 419360512x, DB: J1939_Display) & \\
\hline 目 & (9) Pass & all frames & 10 Symbolic CAN message & CAN1 & ERC1 (ID: 418381839x, DB: J1939_Display) & \\
\hline$\nabla$ & (1) Pass & all frames & Symbolic CAN message & CAN1 & ET1 (ID: 419360256x, DB: J1939_Display) & \\
\hline$\nabla$ & \& Limit & 1 frame per $50 \mathrm{~ms}$ & 7 Symbolic CAN message & CAN1 & ETC1 (ID: 217055747x, DB: J1939_Display) & \\
\hline 目 & (9) Pass & all frames & 4 Symbolic CAN message & CAN1 & ETC2 (ID: 418383107x, DB: J1939_Display) & \\
\hline 目 & $\odot$ Pass & all frames & 7 Symbolic CAN message & CAN1 & ETC7 (ID: 419318275x, DB: J1939_Display) & \\
\hline 目 & Q Limit & 1 frame per $50 \mathrm{~ms}$ & Symbolic CAN message & CAN1 & ETC8 (ID: 217058307x, DB: J1939_Display) & \\
\hline$\nabla$ & (1) Pass & all frames & 7 Symbolic CAN message & CAN1 & FD (ID: 419347712x, DB: J1939_Display) & \\
\hline 目 & (1) Pass & all frames & 7 Symbolic CAN message & CAN1 & HOURS (ID: 419357952x, DB: J1939_Display) & \\
\hline$\nabla$ & Q Limit & 1 frame per $100 \mathrm{~ms}$ & 7 Symbolic CAN message & CAN1 & HRW (ID: 150892043x, DB: J1939_Display) & \\
\hline$\nabla$ & ( P Pass & all frames & 7 Symbolic CAN message & CAN1 & IC1 (ID: 419362304x, DB: J1939_Display) & \\
\hline$\nabla$ & (1) Pass & all frames & 7 Symbolic CAN message & CAN1 & LC (ID: 217989415x, DB: J1939_Display) & \\
\hline 目 & (9) Pass & all frames & 0 Symbolic CAN message & CAN1 & LD (ID: 419315767x, DB: J1939_Display) & \\
\hline 目 & (1) Pass & all frames & 7 Symbolic CAN message & CAN1 & LFE (ID: 419361280x, DB: J1939_Display) & \\
\hline- & & & - & & - & \\
\hline$\nabla$ & $\oplus$ Pass & all frames & Symbolic CAN message & CAN1 & LFE (ID: 419361280x, DB: J1939_Display) & \\
\hline 目 & Q Limit & 1 frame per $1000 \mathrm{~ms}$ & 0 Symbolic CAN message & CAN1 & ML (ID: 419318839x, DB: J1939_Display) & \\
\hline V & Q Limit & 1 frame per $1000 \mathrm{~ms}$ & Symbolic CAN message & CAN1 & OWW (ID: 419286327x, DB: J1939_Display) & \\
\hline V & Q Limit & 1 frame per $100 \mathrm{~ms}$ & Symbolic CAN message & CAN1 & PIS (ID: 218098662x, DB: J1939_Display) & $\equiv$ \\
\hline$\nabla$ & Q Limit & 1 frame per $1000 \mathrm{~ms}$ & 10 Symbolic CAN message & CAN1 & PTO (ID: 419360768x, DB: J1939_Display) & \\
\hline$\nabla$ & (1) Pass & all frames & 10 Symbolic CAN message & CAN1 & RQST (ID: 418053886x, DB: J1939_Display) & \\
\hline 目 & (1) Pass & all frames & Symbolic CAN message & CAN1 & SHUTDN (ID: 419357696x, DB: J1939_Display) & \\
\hline$\nabla$ & Q Limit & 1 frame per $100 \mathrm{~ms}$ & 10 Symbolic CAN message & CAN1 & TC1 (ID: 201392901x, DB: J1939_Display) & \\
\hline$\square$ & $\Theta$ Pass & all frames & 10 Symbolic CAN message & CAN1 & TPCM (ID: 485293824x, DB: J1939_Display) & \\
\hline$\square$ & ( $)$ Pass & all frames & 0 Symbolic CAN message & CAN1 & TPDT (ID: 485228288x, DB: J1939_Display) & \\
\hline$\nabla$ & (1) Pass & all frames & Symbolic CAN message & CAN1 & TRF1 (ID: $419362819 x$, DB: J1939_Display) & \\
\hline$\nabla$ & (1) Pass & all frames & 10 Symbolic CAN message & CAN1 & TSC1 (ID: 201385511x, DB: J1939_Display) & \\
\hline 目 & (1) Pass & all frames & 10 Symbolic CAN message & CAN1 & VDC1 (ID: 419319563x, DB: J1939_Display) & \\
\hline V & Q Limit & 1 frame per $100 \mathrm{~ms}$ & 0 Symbolic CAN message & CAN1 & VDC2 (ID: 418384139x, DB: J1939_Display) & \\
\hline D & $\odot$ Pass & all frames & 10 Symbolic CAN message & CAN1 & VDHR (ID: 419348736x, DB: J1939_Display) & \\
\hline$\nabla$ & (1) Pass & all frames & 10 Symbolic CAN message & CAN1 & VEP1 (ID: 419362560x, DB: J1939_Display) & \\
\hline
\end{tabular}

This report is available at no cost from the National Renewable Energy Laboratory (NREL) at www.nrel.gov/publications. 


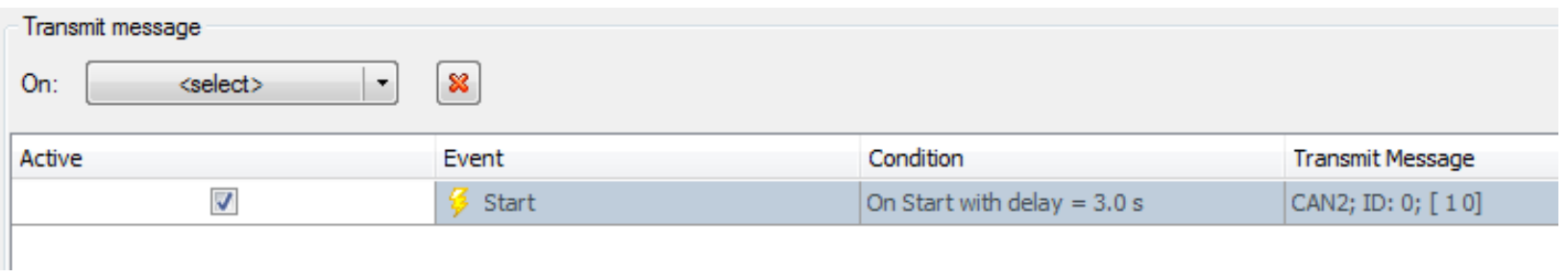

This report is available at no cost from the National Renewable Energy Laboratory (NREL) at www.nrel.gov/publications. 